Article

\title{
Synthesis and In Vitro Cytotoxicity and Antibacterial Activity of Novel 1,2,3-Triazol-5-yl-Phosphonates
}

\author{
Anna Tripolszky ${ }^{1}$, Emese Tóth ${ }^{1}$, Pál Tamás Szabó ${ }^{2}$, László Hackler Jr. ${ }^{3}$, Beáta Kari ${ }^{3}$, \\ László G. Puskás ${ }^{3, *}$ and Erika Bálint ${ }^{1, * \text { (D) }}$ \\ 1 Department of Organic Chemistry and Technology, Budapest University of Technology and Economics, \\ H-1521 Budapest, Hungary; tripolszky.anna@mail.bme.hu (A.T.); emesetoth92@gmail.com (E.T.) \\ 2 MS Metabolomics Laboratory, Instrumentation Center, Research Centre for Natural Sciences, Hungarian \\ Academy of Sciences, Magyar tudósok krt. 2., 1117 Budapest, Hungary; szabo.pal@ttk.mta.hu \\ 3 Avidin Ltd., Alsó kikötő sor 11/D, H-6726 Szeged, Hungary; 1.hackler@avidinbiotech.com (L.H.J.); \\ b.kari@avidinbiotech.com (B.K.) \\ * Correspondence: laszlo@avidinbiotech.com (L.G.P.); ebalint@mail.bme.hu (E.B.); \\ Tel.: +36-62-202-107 (L.G.P.); +36-1-463-3653(E.B.)
}

Academic Editor: Pierre-Antoine Bouit

Received: 9 May 2020; Accepted: 4 June 2020; Published: 6 June 2020

\begin{abstract}
Novel 1,2,3-triazol-5-yl-phosphonates were prepared by the copper(I)-catalyzed domino reaction of phenylacetylene, organic azides and dialkyl phosphites. The process was optimized on the synthesis of the dibutyl (1-benzyl-4-phenyl-1H-1,2,3-triazol-5-yl)phosphonate in respect of the catalyst, the base and the solvent, as well as of the reaction parameters (molar ratio of the starting materials, atmosphere, temperature and reaction time). The method elaborated could be applied to a range of organic azides and dialkyl phosphites, which confirmed the large scope and the functional group tolerance. The in vitro cytotoxicity on different cell lines and the antibacterial activity of the synthesized 1,2,3-triazol-5-yl-phosphonates was explored. According to the $\mathrm{IC}_{50}$ values determined, only modest antibacterial effect was detected, while some derivatives showed moderate activity against human promyelocytic leukemia HL-60 cells.
\end{abstract}

Keywords: 1,2,3-triazoles; triazolyl phosphonates; copper(I) catalyst; domino reaction; multicomponent reaction; anticancer activity

\section{Introduction}

Heterocyclic scaffolds bearing phosphonate moieties have been attracting continuous interest due to their importance in synthetic- and medicinal chemistry, as well as in the agriculture and plastic industry [1-4]. One of the most convenient and efficient tools for the preparation of heterocyclic phosphonates are multicomponent reactions [5], which usually utilize simple starting materials, and meet several criteria of a theoretical "ideal synthesis", such as high atom economy, fast and simple accomplishment, ability to save time and energy and being as environmentally-friendly as possible [6,7]. They may also be feasible for the creation of large libraries of structurally related compounds.

In the last decades, 1,2,3-triazoles have received significant attention due to the wide range of their possible applications in materials science, biochemistry or even in drug design [8-10]. Compounds containing the 1,2,3-triazole scaffold may have versatile biological activities, such as antibacterial, antiviral, antifungal, anticancer or anti-inflammatory effects [11-13]. Some novel triazole-based heterocycles showed activity against bacterial strains (Bacillus subtilis and Escherichia coli) [14-16], and in vitro cytotoxicity against tumor cell lines HL-60 (myeloid leukemia), MCF-7 (breast cancer), A549 (lung cancer) and HCT-116 (colon cancer) [17-19]. Furthermore, the unique structural properties 
of 1,2,3-triazoles enable the introduction of various functional groups obtaining new biologically active molecules.

1,2,3-Triazolyl phosphonates combine the advantages of the triazole- and the phosphonate moieties [20]. Several derivatives showed anti-HIV effect [21,22], were investigated in protein binding assays [23] or could be appropriate for bioconjugation [24,25].

The Huisgen 1,3-dipolar cycloaddition [26,27] between azides and alkynyl phosphonates is one of the most common synthetic routes towards 1,2,3-triazol-5-yl-phosphonates (Table 1). Hall and Trippett studied the cycloaddition of ethyl (diethoxyphosphinyl)propynoate and methyl azidoacetate in the absence of any catalyst in boiling toluene (Table 1, Entry 1) [28]. The reaction was not selective; two regioisomers, 1,2,3-triazol-5-yl-phosphonate (1) and 1,2,3-triazol-4-yl-phosphonate (2), were formed in a ratio of ca. 2:1, respectively. Trifluoromethylated triazolyl phosphonates were also synthesized by the catalyst-free addition of tert-butyl azidoacetate to diisopropyl 3,3,3-trifluoroprop-1-ynylphosphonate at room temperature (Table 1, Entry 2) [29]. The click reaction of benzyl azide and diethyl (ethynyl)phosphonates was also carried out in the presence of copper(II) sulfate pentahydrate and sodium ascorbate in DMF (Table 1, Entry 3) [30]. The corresponding 1,2,3-triazol-5-yl-phosphonates (1) were obtained selectively at $170^{\circ} \mathrm{C}$ after $12 \mathrm{~h}$. Odinets and co-workers performed the cycloaddition of $\omega$-phosphorylalkyl azide to tetramethoxy acetylenediphosphonate in water (Table 1, Entry 4) [31]. A microwave-assisted reaction was also reported, in which diethyl (azidomethyl)phosphonate was reacted with diethyl prop-1-ynylphosphonate under catalyst- and solvent-free conditions (Table 1, Entry 5) [32].

Table 1. Cycloaddition of azides and alkynyl phosphonates.

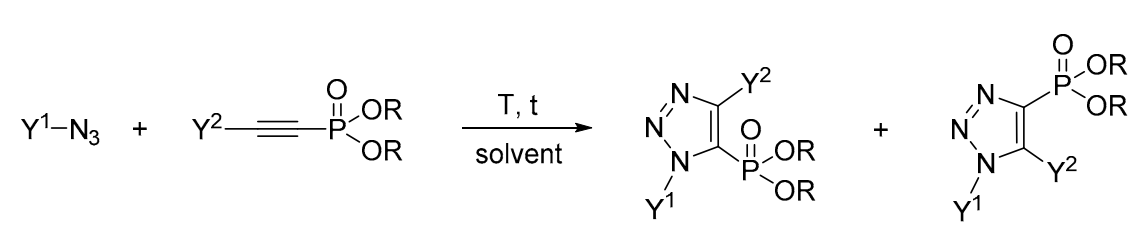

1

2

\begin{tabular}{|c|c|c|c|c|c|c|c|c|c|c|}
\hline \multirow{2}{*}{ Entry } & \multirow[b]{2}{*}{$\mathbf{Y}^{1}$} & \multirow[b]{2}{*}{$Y^{2}$} & \multirow{2}{*}{$\mathbf{R}$} & \multirow[b]{2}{*}{ Cat. } & \multirow[b]{2}{*}{ Solvent } & \multirow[b]{2}{*}{$\mathrm{T}, \mathrm{t}$} & \multicolumn{2}{|c|}{ Product Ratio (\%) } & \multirow{2}{*}{ Yield (\%) } & \multirow[b]{2}{*}{ Ref. } \\
\hline & & & & & & & 1 & 2 & & \\
\hline 1 & $\mathrm{CH}_{2} \mathrm{COOMe}$ & COOEt & Et & - & toluene & $110^{\circ} \mathrm{C}$ & 64 & 36 & - & [28] \\
\hline 2 & $\mathrm{CH}_{2} \mathrm{COO}^{t} \mathrm{Bu}$ & $\mathrm{CF}_{3}$ & ${ }^{i} \operatorname{Pr}$ & - & DEE & $25^{\circ} \mathrm{C}, 20 \mathrm{~h}$ & 75 & 25 & 90 & [29] \\
\hline 3 & Bn & $\begin{array}{c}\mathrm{Ph}, 4-\mathrm{MeC}_{6} \mathrm{H}_{4} \\
\text { 4- } \mathrm{FC}_{6} \mathrm{H}_{4} \text {, etc. }\end{array}$ & Et & $\mathrm{CuSO}_{4} \cdot 5 \mathrm{H}_{2} \mathrm{O} / \mathrm{NaAsc}$ & DMF & $170^{\circ} \mathrm{C}, 12 \mathrm{~h}$ & 100 & 0 & $83-92$ & [30] \\
\hline 4 & $(\mathrm{EtO})_{2} \mathrm{P}(\mathrm{O})\left(\mathrm{CH}_{2}\right)_{2}$ & $(\mathrm{MeO})_{2} \mathrm{P}(\mathrm{O})$ & $\mathrm{Me}$ & - & water & $\begin{array}{l}25^{\circ} \mathrm{C}, 36 \mathrm{~h} \\
\text { or } 60^{\circ} \mathrm{C}, 2 \mathrm{~h}\end{array}$ & & & 95 & [31] \\
\hline 5 & $(\mathrm{EtO})_{2} \mathrm{P}(\mathrm{O}) \mathrm{CH}_{2}$ & $\mathrm{Me}$ & Et & - & - & $\begin{array}{l}\mathrm{MW}, 90^{\circ} \mathrm{C} \\
20 \mathrm{~min}\end{array}$ & 34 & 66 & 78 & [32] \\
\hline
\end{tabular}

Although the 1,3-dipolar cycloaddition is an important synthetic possibility of triazolyl phosphonates, the preparation of the starting alkynyl phosphonate derivatives is a real challenge. By the development of multicomponent approaches for this compound family, utilization of simple building blocks as starting materials may become available.

Several examples were reported on the preparation of 1,2,3-triazol-4-yl-phosphonates by domino or three-component reactions [33,34], however, to the best of our knowledge, only one example mentions the multicomponent synthesis of 1,2,3-triazol-5-yl-phosphonates [20]. Li and co-workers carried out the domino reaction of terminal alkynes, azides, and diethyl-, diisopropyl- or dibenzyl phosphite in the presence of copper(I) chloride as the catalyst (Scheme 1).

The mechanism of the three-component reaction has also been investigated [20]. A detailed proposal in Scheme 2 indicates the three possible pathways $(\mathbf{A}-\mathbf{C})$ of the reaction. According to pathway A, the acetylene reacts with the dialkyl phosphite by an oxidative coupling to give alkynylphosphonate 5, which may react with the azide by click reaction to generate the 1,2,3-triazol-5-yl-phosphonate (3). 
Based on pathway B, the aerobic oxidative coupling of the dialkyl phosphite with the in situ-formed organocopper intermediate (6) may lead to triazol-5-yl-phosphonate (3). While in pathway $\mathbf{C}$, the click reaction of acetylene with azide provides triazole 7 , which undergoes an oxidative coupling with the dialkyl phosphite resulting in product 3 . It was concluded that the reaction took place through pathway B.

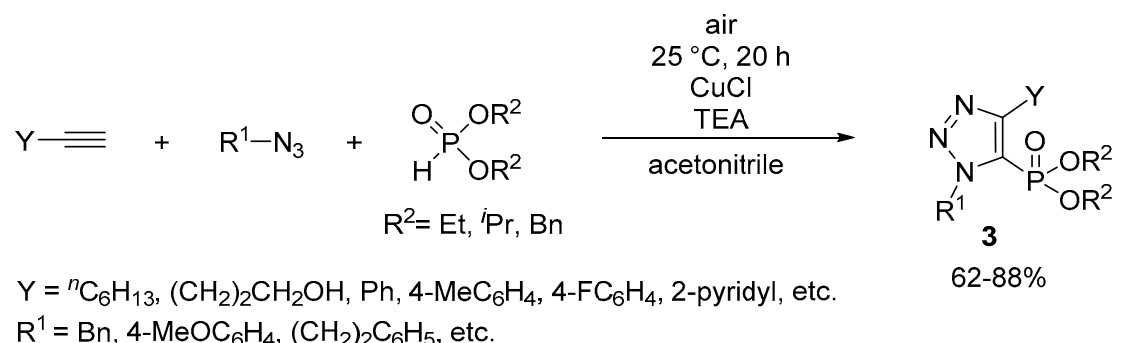

Scheme 1. Synthesis of 1,2,3-triazol-5-yl-phosphonates (3).

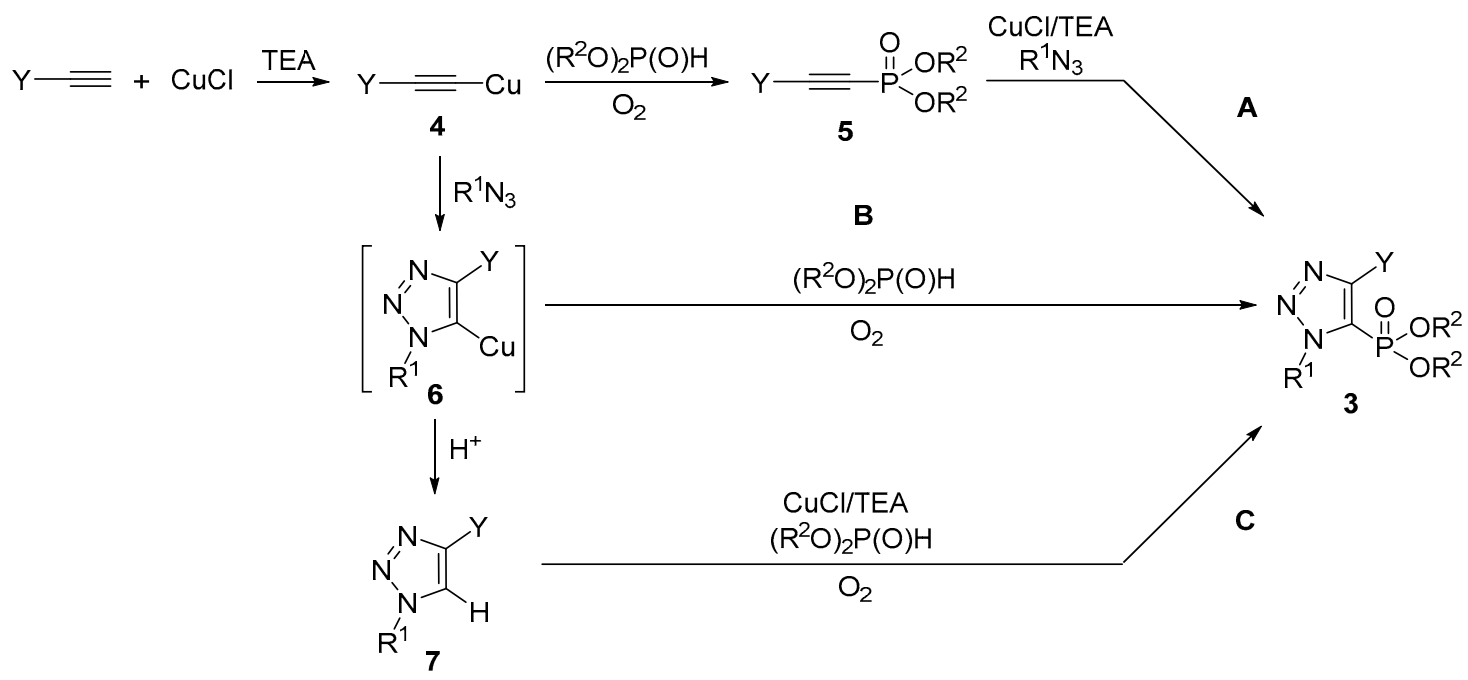

Scheme 2. Proposed reaction mechanism for the $\mathrm{Cu}(\mathrm{I})$-catalyzed domino reaction [20].

In this paper, we report on the synthesis of novel 1,2,3-triazol-5-yl-phosphonates by the copper(I)-catalyzed three-component domino reaction of phenylacetylene, various organic azides and dialkyl phosphites. The biological activity of the compounds synthesized was also studied in antibacterial activity and in vitro cytotoxicity assays.

\section{Results and Discussion}

In our prior work, the copper(I)-catalyzed domino reaction of phenylacetylene, benzyl azide and diethyl phosphite was investigated [35]. The results reported herein include a comprehensive optimization of the domino reaction using dibutyl phosphite (DBP) as a phosphorus reagent, in respect of the molar ratio of the starting materials, the atmosphere, the additives (catalyst, base and solvent), and of the temperature and the reaction time as well (Table 2).

At first, the multicomponent reaction was performed in the presence of $10 \mathrm{~mol} \%$ of $\mathrm{CuCl}$ as a catalyst and two equivalents of TEA (triethylamine) as a base at room temperature in acetonitrile under different atmospheres. Reacting the three components at a molar ratio of 1:1.1:1.1 under nitrogen atmosphere, the 1-benzyl-4-phenyl-1H-1,2,3-triazole (9) $\left\{[\mathrm{M}+\mathrm{H}]^{+}\right.$found $=236.1165, \mathrm{C}_{15} \mathrm{H}_{14} \mathrm{~N}_{3}$ requires 236.1188\} was obtained as the main product instead of the desired triazol-5-yl-phosphonate (8) (Table 2, Entry 1). Repeating the reaction using continuous air bubbling, the triazol-5-yl-phosphonate (8) was formed in 55\%, along with $42 \%$ of the "click product" (9) and 3\% of dibutyl (phenylethynyl)phosphonate 
(10) $\left\{{ }^{31} \mathrm{P} \mathrm{NMR}\left(\mathrm{CDCl}_{3}\right) \delta-5.8 ;[\mathrm{M}+\mathrm{H}]^{+}\right.$found $=295.1440, \mathrm{C}_{16} \mathrm{H}_{24} \mathrm{O}_{3} \mathrm{P}$ requires 295.1463\} (Table 2, Entry 2). Applying a continuous oxygen bubbling, the proportion of alkynylphosphonate (10) significantly increased and the 1,2,3-triazol-5-yl-phosphonate (8) was obtained only in $24 \%$ (Table 2, Entry 3). After that, the effect of various bases was investigated, thus the domino reaction was also carried out in the presence of DPA (dipropylamine), DIPA (diisopropylamine) or DIPEA ( $N, N$-diisopropylethylamine) (Table 2, Entries 4-6). In terms of the formation of the desired 1,2,3-triazol-5-yl-phosphonate (8), TEA was proved to be the most efficient. The effect of the solvent was also studied, from among the solvents tried out (MeCN, DMF, DCM, THF and $\mathrm{EtOH}), \mathrm{MeCN}$ turned out as the most suitable (Table 2, Entries 2 and 7-10). In the next step, the counterion of the copper catalyst was varied. The reaction was performed with $\mathrm{CuCl}, \mathrm{CuBr}, \mathrm{CuI}$ or $\mathrm{CuSO}_{4} \cdot 5 \mathrm{H}_{2} \mathrm{O} / \mathrm{NaAsc}$, and the best result was achieved using $\mathrm{CuCl}$ (Table 2, Entries 2,11-13). Increasing the amount of dibutyl phosphite to two equivalents, the proportion of the desired product (8) could be further improved (59\%) (Table 2, Entry 14). Applying a larger excess of dibutyl phosphite or more $\mathrm{CuCl}$ did not favor the formation of the triazol-5-yl-phosphonate (8) (Table 2, Entries 15 and 16). Finally, the effect of the temperature was investigated. Neither lowering $\left(0{ }^{\circ} \mathrm{C}\right)$ nor raising $\left(50{ }^{\circ} \mathrm{C}\right)$ the temperature caused improvement in the ratio of 1,2,3-triazol-5-yl-phosphonate (8) (Table 2, Entries 17 and 18). The best result was obtained using two equivalents of dibutyl phosphite in the presence of two equivalents of TEA and $10 \mathrm{~mol} \%$ of $\mathrm{CuCl}$ at room temperature in acetonitrile and continuous air bubbling (Table 2, Entry 14).

Table 2. Optimization of the domino reaction of phenylacetylene, benzyl azide and dibutyl phosphite.
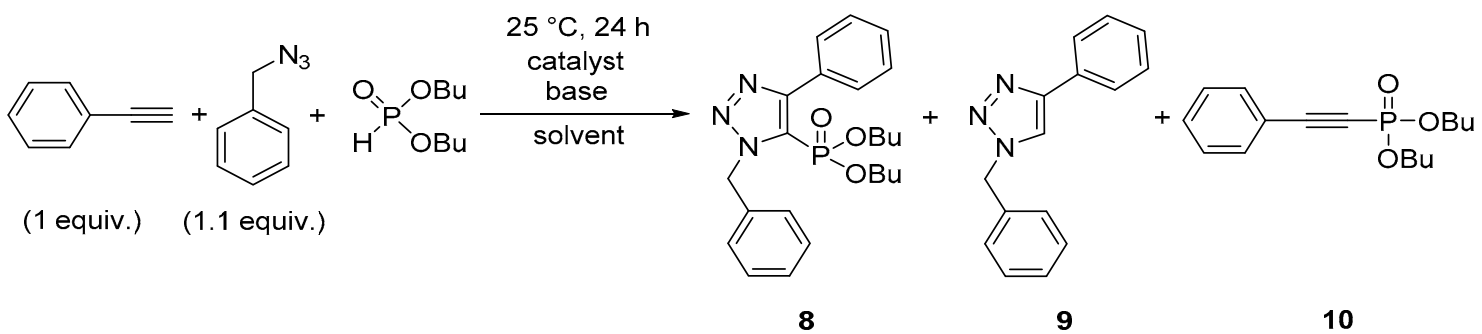

\begin{tabular}{|c|c|c|c|c|c|c|c|c|}
\hline \multirow{2}{*}{ Entry } & \multirow{2}{*}{ DBP (Equiv.) } & \multirow{2}{*}{ Condition } & \multirow{2}{*}{$\begin{array}{c}\text { Catalyst (10 } \\
\text { mol } \%)\end{array}$} & \multirow{2}{*}{ Base (2 Equiv.) } & \multirow{2}{*}{ Solvent } & \multicolumn{3}{|c|}{ Product Composition (\%) } \\
\hline & & & & & & 8 & 9 & 10 \\
\hline 1 & 1.1 & $\mathrm{~N}_{2}$ bubbling & $\mathrm{CuCl}$ & TEA & $\mathrm{MeCN}$ & 22 & 77 & 1 \\
\hline 2 & 1.1 & air bubbling & $\mathrm{CuCl}$ & TEA & $\mathrm{MeCN}$ & 55 & 42 & 3 \\
\hline 3 & 1.1 & $\mathrm{O}_{2}$ bubbling & $\mathrm{CuCl}$ & TEA & $\mathrm{MeCN}$ & 24 & 70 & 6 \\
\hline 4 & 1.1 & air bubbling & $\mathrm{CuCl}$ & DPA & $\mathrm{MeCN}$ & 46 & 49 & 5 \\
\hline 5 & 1.1 & air bubbling & $\mathrm{CuCl}$ & DIPA & $\mathrm{MeCN}$ & 54 & 44 & 2 \\
\hline 6 & 1.1 & air bubbling & $\mathrm{CuCl}$ & DIPEA & $\mathrm{MeCN}$ & 35 & 63 & 2 \\
\hline 7 & 1.1 & air bubbling & $\mathrm{CuCl}$ & TEA & DMF & 41 & 57 & 2 \\
\hline 8 & 1.1 & air bubbling & $\mathrm{CuCl}$ & TEA & DCM & 43 & 56 & 1 \\
\hline 9 & 1.1 & air bubbling & $\mathrm{CuCl}$ & TEA & THF & 21 & 78 & 1 \\
\hline 10 & 1.1 & air bubbling & $\mathrm{CuCl}$ & TEA & $\mathrm{EtOH}$ & 39 & 59 & 2 \\
\hline 11 & 1.1 & air bubbling & $\mathrm{CuBr}$ & TEA & $\mathrm{MeCN}$ & 42 & 56 & 2 \\
\hline 12 & 1.1 & air bubbling & $\mathrm{CuI}$ & TEA & $\mathrm{MeCN}$ & 26 & 72 & 2 \\
\hline 13 & 1.1 & air bubbling & $\mathrm{CuSO}_{4} \cdot 5 \mathrm{H}_{2} \mathrm{O} / \mathrm{NaAsc}$ & TEA & $\mathrm{MeCN}$ & 0 & 100 & 0 \\
\hline 14 & 2 & air bubbling & $\mathrm{CuCl}$ & TEA & $\mathrm{MeCN}$ & 59 & 37 & 4 \\
\hline 15 & 3 & air bubbling & $\mathrm{CuCl}$ & TEA & $\mathrm{MeCN}$ & 51 & 45 & 4 \\
\hline $16^{b}$ & 2 & air bubbling & $\mathrm{CuCl}$ & TEA & $\mathrm{MeCN}$ & 49 & 49 & 2 \\
\hline $17^{c}$ & 2 & air bubbling & $\mathrm{CuCl}$ & TEA & $\mathrm{MeCN}$ & 36 & 62 & 2 \\
\hline $18^{d}$ & 2 & air bubbling & $\mathrm{CuCl}$ & TEA & $\mathrm{MeCN}$ & 23 & 75 & 2 \\
\hline
\end{tabular}

a Based on HPLC (222 nm). ${ }^{b}$ The reaction was performed using $15 \mathrm{~mol} \%$ of $\mathrm{CuCl} .{ }^{\mathrm{c}}$ The reaction was carried out at $0{ }^{\circ} \mathrm{C}$. ${ }^{\mathrm{d}}$ The reaction was carried out at $50{ }^{\circ} \mathrm{C}$.

Applying the optimal parameters, the reaction time was also investigated. It was found that, during the first eight hours, the proportion of the desired dibutyl (1-benzyl-4-phenyl-1H-1,2,3-triazol-5-yl)phosphonate (8) increased, and the proportion of the 1-benzyl-4-phenyl-1H-1,2,3-triazole (9) continuously decreased (Figure 1). It should be noted that the dibutyl (phenylethynyl)phosphonate (10) did not form in a significant amount during the observed $24 \mathrm{~h}$. Based on Figure 1, a reaction time of eight hours was considered as optimal for the domino reactions. 


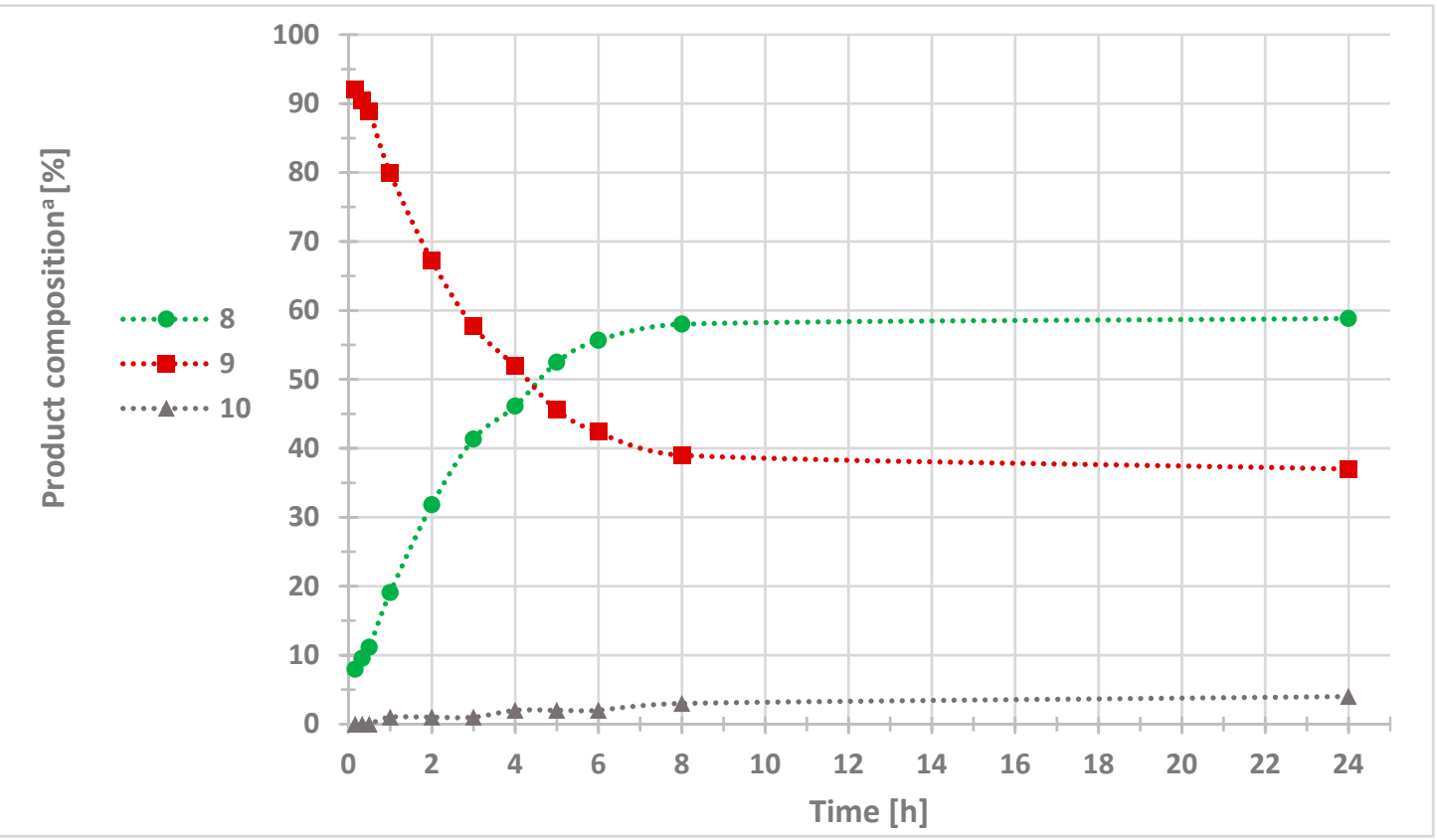

Figure 1. Time dependence of the product composition in the model reaction of phenylacetylene, benzyl azide and dibutyl phosphite. Conditions: phenylacetylene (1 equiv.), benzyl azide (1.1 equiv.), dibutyl phosphite ( 2 equiv.), $\mathrm{CuCl}$ ( 0.1 equiv.) and TEA ( 2 equiv.) were stirred in $\mathrm{MeCN}$ with continuous air bubbling at $25^{\circ} \mathrm{C}$ for $24 \mathrm{~h}$. ${ }^{\text {a }}$ Based on HPLC (222 nm).

In the next series of experiments, the three-component reaction of phenylacetylene, various benzyl azides and dialkyl phosphites was investigated under the optimized conditions (Scheme 3). First, the domino reaction of phenylacetylene and benzyl azide was carried out with a wide range of dialkyl phosphites. Using dimethyl phosphite, the dimethyl (1-benzyl-4-phenyl-1,2,3-triazol-5-yl)phosphonate (11) was isolated in a yield of 53\%. Performing the reactions with diethyl- or dipropyl phosphite, the product 12 and 13 was prepared in a yield of $62 \%$ and $43 \%$, respectively. Changing for a dialkyl phosphite containing branched alkyl chains, such as diisopropyl phosphite, the desired triazol-5-yl-phosphonate (14) was obtained in a yield of $40 \%$ after column chromatography. The dibutyl (1-benzyl-4-phenyl-1H-1,2,3-triazol-5-yl)phosphonate (8) was isolated from the experiments of Table 2, Entry 14 in a yield of $49 \%$. Applying a dialkyl phosphite incorporating long alkyl chains, such as dipentyl phosphite, the corresponding dipentyl (1-benzyl-4-phenyl-1,2,3-triazol-5-yl)phosphonate (15) was prepared in a yield of $34 \%$. After that, the domino reaction was performed with substituted benzyl azides (4-methylbenzyl azide 2-, 3- or 4-fluorobenzyl azide or 4-(trifluoromethyl)benzyl azide). Carrying out the reaction of phenylacetylene and 4-methylbenzyl azide with dimethyl-, diethyl- or dibutyl phosphite, the desired triazol-5-yl-phosphonates (16-18) could be isolated in yields of $40 \%$, $52 \%$ and $42 \%$, respectively. Finally the domino reaction of phenylacetylene, and dibutyl phosphite was also carried out with 2-, 3- or 4-fluorobenzyl azide or 4-(trifluoromethyl)benzyl azide, and the corresponding dibutyl (1-benzyl-4-phenyl-1H-1,2,3-triazol-5-yl)phosphonate derivatives (19-22) were synthesized in yields of 30-39\%.

The $\mathrm{CuCl}$-catalyzed domino reaction was also carried out with aliphatic azides, such as octyl or iso-octyl azide using the optimized conditions (Scheme 4). In the reactions of phenylacetylene, octyl azide and dimethyl-, diethyl- or dibutyl phosphite, the corresponding 1-octyl-4-phenyl-1H-1,2,3-triazolyl phosphonates (23-25) were prepared in yields of 43-58\%. Finally, iso-octyl azide was reacted with phenylacetylene and dibutyl phosphite, and the desired product (26) was obtained in a yield of $28 \%$, possibly due to the steric hindrance of the 2-ethylhexyl group. 


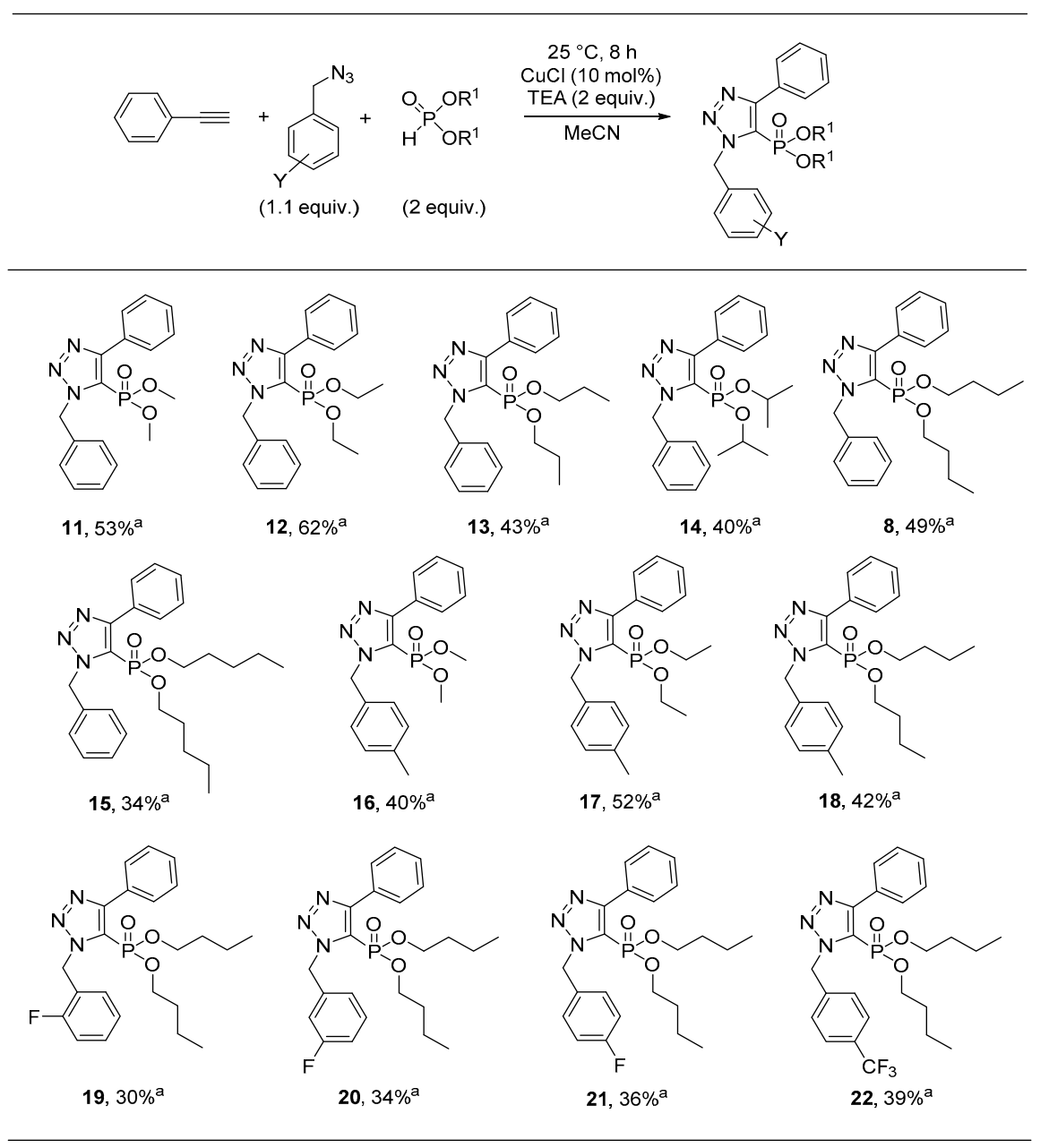

Scheme 3. Domino reaction of phenylacetylene, substituted benzyl azides and dialkyl phosphites.

a Isolated yield.

The multicomponent approach developed is a fast and simple methodology for the synthesis of 1,2,3-triazol-5-yl-phosphonates, which utilizes simple starting materials and applies milder reaction conditions compared to the preparation of these compounds by 1,3-dipolar cycloaddition. In contrast to a previous report dealing with a similar topic [20], besides a comprehensive optimization, we have provided exact product compositions, including the amount of the "click product" and the amount of the (phenylethynyl)phosphonate, respectively. The scope of the reaction was extended for 15 novel derivatives. (Copies of ${ }^{31} \mathrm{P},{ }^{1} \mathrm{H}$, and ${ }^{13} \mathrm{C}$ NMR spectra for all compounds synthesized are presented in Supplementary Materials).

Finally, the biological activity of the synthesized 1,2,3-triazol-5-yl-phosphonates $(\mathbf{8}, \mathbf{1 1 - 2 6 )}$ was investigated. On the one hand, the antibacterial activity of the compounds was tested on GFP producing Gram-positive (Bacillus subtilis) and Gram-negative (Escherichia coli) bacterial cells. The GFP producing bacteria are an effective tool for screening for antibacterial activity since GFP signal measured via fluorimetry is proportional to the number of bacterial cells. Active compounds would kill bacterial cells, which results in the decrease in GFP fluorescence signal, therefore it is suitable for evaluating the antimicrobial effect of different agents. On the other hand, in vitro cytotoxicity assessments were performed on three different cell lines, such as human lung adenocarcinoma (A549), mouse fibroblast (NIH/3T3) as healthy cell line and human promyelocytic leukemia (HL-60). Table 3 contains the determined $\mathrm{IC}_{50}$ values in antimicrobial and cytotoxicity assays. According to the results, only modest antibacterial activity was detected against the more sensitive Bacillus subtilis strain. The $\mathrm{IC}_{50}$ values of triazolyl phosphonates $(\mathbf{8}, \mathbf{1 3}, \mathbf{1 5}, \mathbf{1 6}, \mathbf{1 9 - 2 2}$ 
and 26), which showed some activity against NIH/3T3 and/or HL-60 cells fall in the range of 9.7 and $27.5 \mu \mathrm{M}$. Dimethyl [1-(4-methylbenzyl)-4-phenyl-1,2,3-triazol-5-yl]phosphonate (16) and dibutyl [1-(4-trifluoromethyl)-4-phenyl-1,2,3-triazol-5-yl]phosphonate (22) proved to be the most active compounds, which showed activity in the 10 micromolar range against HL-60 cells.

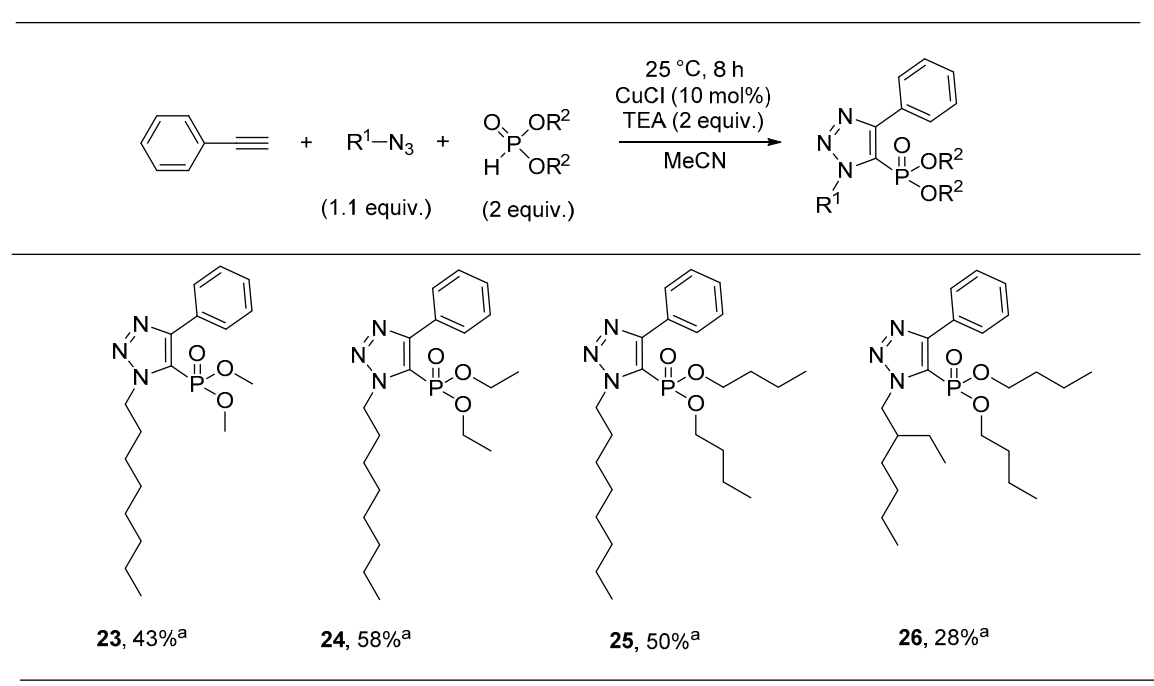

Scheme 4. Domino reaction of phenylacetylene, aliphatic azides and dialkyl phosphites. ${ }^{\text {a }}$ Isolated yield.

Table 3. Summary of biological activity measurements.

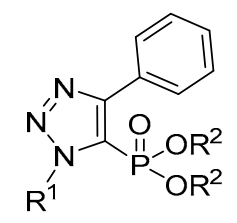

\begin{tabular}{|c|c|c|c|c|c|c|c|}
\hline \multirow{2}{*}{ Compound } & \multirow{2}{*}{$\mathbf{R}^{1}$} & \multirow{2}{*}{$\mathbf{R}^{2}$} & \multicolumn{2}{|c|}{ Antibacterial Activity $\left(\mathrm{IC}_{50}, \mu \mathrm{M}\right)$} & \multicolumn{3}{|c|}{ In Vitro Cytotoxicity $\left(\mathrm{IC}_{50}, \mu \mathrm{M}\right)$} \\
\hline & & & B. subtilis & E. coli & A549 & $\mathrm{NIH} / 3 \mathrm{~T} 3$ & HL-60 \\
\hline 8 & $\mathrm{Bn}$ & $\mathrm{Bu}$ & $>30$ & $>30$ & $>30$ & $27.5 \pm 1.4$ & $>30$ \\
\hline 11 & $\mathrm{Bn}$ & $\mathrm{Me}$ & $>30$ & $>30$ & $>30$ & $>30$ & $>30$ \\
\hline 12 & $\mathrm{Bn}$ & Et & $>30$ & $>30$ & $>30$ & $>30$ & $>30$ \\
\hline 13 & $\mathrm{Bn}$ & $\operatorname{Pr}$ & $29.3 \pm 1.2$ & $>30$ & $>30$ & $>30$ & $12.6 \pm 1.7$ \\
\hline 14 & $\mathrm{Bn}$ & ${ }^{i} \operatorname{Pr}$ & $>30$ & $>30$ & $>30$ & $>30$ & $>30$ \\
\hline 15 & $\mathrm{Bn}$ & $\mathrm{Pn}$ & $23.9 \pm 1.0$ & $>30$ & $>30$ & $26.2 \pm 1.1$ & $15.4 \pm 1.2$ \\
\hline 16 & $4-\mathrm{MeC}_{6} \mathrm{H}_{4}$ & $\mathrm{Me}$ & $>30$ & $>30$ & $>30$ & $19.8 \pm 1.2$ & $11.0 \pm 1.2$ \\
\hline 17 & $4-\mathrm{MeC}_{6} \mathrm{H}_{4}$ & $\mathrm{Et}$ & $>30$ & $>30$ & $>30$ & $>30$ & $>30$ \\
\hline 18 & $4-\mathrm{MeC}_{6} \mathrm{H}_{4}$ & $\mathrm{Bu}$ & $18.2 \pm 1.0$ & $>30$ & $>30$ & $>30$ & $>30$ \\
\hline 19 & $2-\mathrm{FC}_{6} \mathrm{H}_{4}$ & $\mathrm{Bu}$ & $19.3 \pm 1.0$ & $>30$ & $>30$ & $27.5 \pm 1.1$ & $11.7 \pm 1.2$ \\
\hline 20 & $3-\mathrm{FC}_{6} \mathrm{H}_{4}$ & $\mathrm{Bu}$ & $>30$ & $>30$ & $>30$ & $>30$ & $15.4 \pm 1.2$ \\
\hline 21 & $4-\mathrm{FC}_{6} \mathrm{H}_{4}$ & $\mathrm{Bu}$ & $23.2 \pm 1.1$ & $>30$ & $>30$ & $>30$ & $16.6 \pm 1.3$ \\
\hline 22 & $4-\mathrm{CF}_{3} \mathrm{C}_{6} \mathrm{H}_{4}$ & $\mathrm{Bu}$ & $>30$ & $>30$ & $>30$ & $23.1 \pm 1.2$ & $9.7 \pm 1.1$ \\
\hline 23 & Oct & $\mathrm{Me}$ & $>30$ & $>30$ & $>30$ & $>30$ & $>30$ \\
\hline 24 & Oct & Et & $>30$ & $>30$ & $>30$ & $>30$ & $>30$ \\
\hline 25 & Oct & $\mathrm{Bu}$ & $>30$ & $>30$ & $>30$ & $>30$ & $>30$ \\
\hline \multirow[t]{5}{*}{26} & ${ }^{i}$ Oct & $\mathrm{Bu}$ & $29.6 \pm 1.0$ & $>30$ & $>30$ & $>30$ & $26.7 \pm 1.0$ \\
\hline & Doxycycline & & $0.04 \pm 0.01$ & $0.10 \pm 0.02$ & - & - & - \\
\hline & Gentamicin & & $0.49 \pm 0.14$ & $4.23 \pm 0.99$ & - & - & - \\
\hline & Doxorubicin & & - & - & $0.31 \pm 0.24$ & $5.65 \pm 0.81$ & - \\
\hline & Bortezomib & & - & - & - & - & $\begin{array}{l}7.42 \times 10^{-3} \\
2.60 \times 10^{-3}\end{array}$ \\
\hline
\end{tabular}

Data were expressed as mean \pm standard deviation. 


\section{Materials and Methods}

\subsection{General}

The reactions under conventional heating were carried out in an oil bath. The microwave-assisted experiments were performed in a $300 \mathrm{~W}$ CEM Discover focused microwave reactor (CEM Microwave Technology Ltd., Buckingham, UK) equipped with a pressure controller using 5-10 W irradiation under isothermal conditions.

HPLC-MS measurements were performed with an Agilent 1200 liquid chromatography system coupled with a 6130 quadrupole mass spectrometer equipped with an ESI ion source (Agilent Technologies, Palo Alto, CA, USA). The analysis was performed at $40{ }^{\circ} \mathrm{C}$ on a Gemini C18 column (150 $\mathrm{mm} \times 4.6 \mathrm{~mm}, 3 \mu \mathrm{m}$; Phenomenex, Torrance, CA, USA) with a mobile phase flow rate of $0.6 \mathrm{~mL} / \mathrm{min}$. The composition of eluent A was $0.1 \%\left(\mathrm{NH}_{4}\right)(\mathrm{HCOO})$ in water; eluent B was $0.1 \%\left(\mathrm{NH}_{4}\right)(\mathrm{HCOO})$ and $8 \%$ water in acetonitrile. 0-3 min. 5\% B, 3-13 min. gradient, 13-20 min. 100\% B. The injection volume was $5 \mu \mathrm{L}$. The chromatographic profile was registered at $222 \mathrm{~nm}$. The MSD operating parameters were as follows: positive ionization mode, scan spectra from $m / z 120$ to 1200 , drying gas temperature $300^{\circ} \mathrm{C}$, nitrogen flow rate $10 \mathrm{~L} / \mathrm{min}$, nebulizer pressure 60 psi, capillary voltage $4000 \mathrm{~V}$.

High resolution mass spectrometric measurements were performed using a Sciex 5600+ Q-TOF mass spectrometer in positive electrospray mode.

The ${ }^{31} \mathrm{P},{ }^{1} \mathrm{H},{ }^{13} \mathrm{C}$, NMR spectra were taken in $\mathrm{CDCl}_{3}$ solution on a Bruker AV-300 spectrometer operating at 121.5, 300 and $75.5 \mathrm{MHz}$, respectively. Chemical shifts are downfield relative to $85 \%$ $\mathrm{H}_{3} \mathrm{PO}_{4}$ and TMS.

\subsection{General Procedure for the Synthesis of Organic Azides}

\subsubsection{Method A}

To a stirred solution of $10.0 \mathrm{mmol}$ alkyl halides $(1.19 \mathrm{~mL}$ of benzyl bromide, $1.85 \mathrm{~g}$ of 4 -methylbenzyl bromide, $1.21 \mathrm{~mL}$ of 2-fluorobenzyl bromide, $1.23 \mathrm{~mL}$ of 3-fluorobenzyl bromide, $1.25 \mathrm{~mL}$ of 4-fluorobenzyl bromide or $1.55 \mathrm{~mL}$ of 4-(trifluoromethyl)benzyl bromide) in $100 \mathrm{~mL}$ of acetone/ $\mathrm{H}_{2} \mathrm{O}$ 4:1 $(v / v)$ was added $15.0 \mathrm{mmol}(0.98 \mathrm{~g})$ of sodium azide. The reaction mixture was stirred at room temperature for $24 \mathrm{~h}$. After that, the reaction was extracted with $\mathrm{Et}_{2} \mathrm{O}(3 \times 50 \mathrm{~mL})$, dried over $\mathrm{Na}_{2} \mathrm{SO}_{4}$, and concentrated under reduced pressure to give benzyl azides as pale yellow oils.

\subsubsection{Method B}

To a stirred solution of $10.0 \mathrm{mmol}$ alkyl halides $(1.76 \mathrm{~mL}$ of octyl bromide or $1.78 \mathrm{~mL}$ of iso-octyl bromide) in $20 \mathrm{~mL}$ of DMF, $12.0 \mathrm{mmol}(0.78 \mathrm{~g})$ of sodium azide was added. The reaction mixture was stirred at $70{ }^{\circ} \mathrm{C}$ for $24 \mathrm{~h}$ in an oil bath. After, the reaction was extracted with $\mathrm{Et}_{2} \mathrm{O}(3 \times 50 \mathrm{~mL})$, dried over $\mathrm{Na}_{2} \mathrm{SO}_{4}$, and concentrated under reduced pressure to give alkyl azides as pale yellow oils.

The following organic azides were prepared using method A or method B (Table 4):

Table 4. Yield and mass data for the organic azides prepared.

\begin{tabular}{|c|c|c|c|}
\hline $\mathbf{R}^{1} \mathbf{N}_{3}$ & Yield & {$[\mathrm{M}+\mathrm{H}]^{+}$found } & {$[\mathrm{M}+\mathrm{H}]^{+}$requires } \\
\hline $\mathrm{BnN}_{3}[36]$ & $93 \%(1.24 \mathrm{~g})$ & 134.0725 & 134.0718 \\
\hline $4-\mathrm{Me}-\mathrm{BnN}_{3}[37]$ & $80 \%(1.18 \mathrm{~g})$ & 148.0880 & 148.0874 \\
\hline $2-\mathrm{F}-\mathrm{BnN}_{3}[38]$ & $68 \%(1.02 \mathrm{~g})$ & 152.0632 & 152.0624 \\
\hline $3-\mathrm{F}-\mathrm{BnN}_{3}[39]$ & $76 \%(1.14 \mathrm{~g})$ & 152.0633 & 152.0624 \\
\hline $4-\mathrm{F}-\mathrm{BnN}_{3}[37]$ & $83 \%(1.25 \mathrm{~g})$ & 152.0632 & 152.0624 \\
\hline $4-\mathrm{CF}_{3}-\mathrm{BnN}_{3}[40]$ & $86 \%(1.72 \mathrm{~g})$ & 202.0601 & 202.0592 \\
\hline $\mathrm{OctN}_{3}[41]$ & $67 \%(1.04 \mathrm{~g})$ & 156.1514 & 156.1501 \\
\hline${ }^{i} \operatorname{OctN}_{3}[42]$ & $55 \%(0.85 \mathrm{~g})$ & 156.1514 & 156.1501 \\
\hline
\end{tabular}




\subsection{General Procedure for the Synthesis of Dipropyl and Dipentyl Phosphite}

A mixture of $5.0 \mathrm{mmol}(0.64 \mathrm{~mL})$ of diethyl phosphite and 25 equivalents, and $150.0 \mathrm{mmol}$ of alcohol (10.0 mL n-propanol or $14.0 \mathrm{~mL} n$-pentanol) was heated at $175^{\circ} \mathrm{C}$ in a vial in the $\mathrm{MW}$ reactor for 120-135 min. The volatile components were removed in vacuum and the crude product was purified by column chromatography using silica gel as the solid phase and ethyl acetate as the eluent. The following dialkyl phosphites were thus prepared (Table 5):

Table 5. Yield, ${ }^{31} \mathrm{P}$ NMR and MS data for the dialkyl phosphites prepared.

\begin{tabular}{cccccc}
\hline$\left(\mathbf{R}^{\mathbf{2}} \mathbf{O}\right)_{2} \mathbf{P}(\mathbf{O}) \mathbf{H}$ & Yield & $\mathcal{\delta}_{\mathbf{P}}$ in $\mathbf{C D C l}_{\mathbf{3}}$ & $\mathcal{\delta}_{\mathbf{P}}\left[\right.$ lit.] in $\mathbf{C D C l}_{\mathbf{3}}$ & {$[\mathbf{M}+\mathbf{H}]^{+}$found } & {$[\mathbf{M}+\mathbf{H}]^{+}{ }_{\text {requires }}$} \\
\hline$(\mathrm{PrO})_{2} \mathrm{P}(\mathrm{O}) \mathrm{H}$ & $65 \%(0.54 \mathrm{~g})$ & 7.9 & $7.8[43]$ & 167.0833 & 167.0837 \\
$(\mathrm{PentO})_{2} \mathrm{P}(\mathrm{O}) \mathrm{H}$ & $68 \%(0.75 \mathrm{~g})$ & 7.8 & $8.1[43]$ & 223.1462 & 223.1463 \\
\hline
\end{tabular}

\subsection{General Procedure for the Synthesis of 1,2,3-Triazol-5-yl-Phosphonates}

In combination, $1.0 \mathrm{mmol}$ phenylacetylene $(0.12 \mathrm{~mL}), 1.1 \mathrm{mmol}$ organic azide $(0.14 \mathrm{~g}$ of benzyl azide, $0.17 \mathrm{~g}$ of 4-methylbenzyl azide, $0.17 \mathrm{~g}$ of 2-fluorobenzyl azide, $0.17 \mathrm{~g}$ of 3-fluorobenzyl azide, $0.17 \mathrm{~g}$ of 4-fluorobenzyl azide, $0.22 \mathrm{~g}$ of 4-(trifluoromethyl)benzyl azide, $0.18 \mathrm{~g}$ of octyl azide or $0.18 \mathrm{~g}$ of iso-octyl azide) and $2.0 \mathrm{mmol}$ dialkyl phosphite $(0.18 \mathrm{~mL}$ dimethyl phosphite, $0.26 \mathrm{~mL}$ diethyl phosphite, $0.33 \mathrm{~g}$ dipropyl phosphite, $0.33 \mathrm{~mL}$ diisopropyl phosphite, $0.40 \mathrm{~mL}$ dibutyl phosphite, $0.44 \mathrm{~g}$ dipentyl phosphite) were dissolved in acetonitrile $(20 \mathrm{~mL})$. To this was added $2 \mathrm{mmol}(0.28$ $\mathrm{mL})$ triethylamine and $0.10 \mathrm{mmol}(0.02 \mathrm{~g}) \mathrm{CuCl}$. The mixture was stirred at room temperature with continuous air bubbling for $8 \mathrm{~h}$. The resulting solution was extracted with ethyl acetate $(3 \times 30 \mathrm{~mL})$ and the combined organic layers were dried over $\mathrm{Na}_{2} \mathrm{SO}_{4}$. After evaporating the solvent, the crude product was purified by column chromatography using silica gel and ethyl acetate/hexane 1:1 as the eluent and, if it was necessary, by reversed-phase column chromatography using $\mathrm{C}_{18}$-reversed-phase silica gel and the composition of eluent $\mathrm{A}$ was $0.1 \%\left(\mathrm{NH}_{4}\right)(\mathrm{HCOO})$ in water; eluent $\mathrm{B}$ was $0.1 \%\left(\mathrm{NH}_{4}\right)(\mathrm{HCOO})$ and $8 \%$ water in acetonitrile. The following products were thus prepared:

Dimethyl (1-benzyl-4-phenyl-1,2,3-triazol-5-yl)phosphonate (11): yield: 53\% (0.18 g), colorless oil; ${ }^{31} \mathrm{P}$ NMR $\left(\mathrm{CDCl}_{3}\right) \delta 7.5 ;{ }^{1} \mathrm{H} \mathrm{NMR}\left(\mathrm{CDCl}_{3}\right) \delta 3.40\left(\mathrm{~d}, 6 \mathrm{H},{ }^{3} J_{\mathrm{HP}}=11.8, \mathrm{OCH}_{3}\right), 6.01\left(\mathrm{~s}, 2 \mathrm{H}, \mathrm{CH}_{2} \mathrm{Ph}\right), 7.26-7.36(\mathrm{~m}$, $\left.3 \mathrm{H}, \mathrm{C}_{3}, \mathrm{H}, \mathrm{C}_{4}, \mathrm{H}\right), 7.36-7.45\left(\mathrm{~m}, 5 \mathrm{H}, \mathrm{C}_{3} \mathrm{H}, \mathrm{C}_{4} \mathrm{H}, \mathrm{C}_{2}, \mathrm{H}\right), 7.74\left(\mathrm{dd}, 2 \mathrm{H},{ }^{3} J_{\mathrm{HH}}=7.4, J_{\mathrm{HH}}=2.2, \mathrm{C}_{2} \mathrm{H}\right) ;{ }^{13} \mathrm{C}$ $\operatorname{NMR}\left(\mathrm{CDCl}_{3}\right) \delta 53.0\left(\mathrm{~d},{ }^{2} J_{\mathrm{CP}}=5.1, \mathrm{OCH}_{3}\right), 54.3\left(\mathrm{CH}_{2} \mathrm{Ph}\right), 120.5\left(\mathrm{~d},{ }^{1} J_{\mathrm{CP}}=219.4, \mathrm{P}(\mathrm{O}) \mathrm{C}=\right), 128.2\left(\mathrm{C}_{2}\right)$, $128.3\left(\mathrm{C}_{2^{\prime}}\right), 128.5\left(\mathrm{C}_{4^{\prime}}\right), 128.8\left(\mathrm{C}_{3^{\prime}}\right), 129.1\left(\mathrm{C}_{3}\right), 129.2\left(\mathrm{C}_{1}\right), 130.0\left(\mathrm{C}_{4}\right), 135.9\left(\mathrm{C}_{1^{\prime}}\right), 153.9\left(\mathrm{~d},{ }^{2} J_{\mathrm{CP}}=19.5\right.$, $\mathrm{PhC}=) ;[\mathrm{M}+\mathrm{H}]^{+}$found $=344.1161, \mathrm{C}_{17} \mathrm{H}_{19} \mathrm{~N}_{3} \mathrm{O}_{3} \mathrm{P}$ requires 344.1164 .

Diethyl (1-benzyl-4-phenyl-1,2,3-triazol-5-yl)phosphonate (12): yield: 62\% (0.23 g), colorless oil; ${ }^{31} \mathrm{P} \mathrm{NMR}$ $\left(\mathrm{CDCl}_{3}\right) \delta 4.4 ; \delta[20]\left(\mathrm{CDCl}_{3}\right) \delta 4.53 ;{ }^{1} \mathrm{H} \mathrm{NMR}\left(\mathrm{CDCl}_{3}\right) \delta 0.98\left(\mathrm{t}, 6 \mathrm{H},{ }^{3} \mathrm{~J}_{\mathrm{HH}}=7.1, \mathrm{OCH}_{2} \mathrm{CH}_{3}\right), 3.58-3.72$ $\left(\mathrm{m}, 2 \mathrm{H}, \mathrm{OCH}_{2} \mathrm{CH}_{3}\right), 3.82-3.95\left(\mathrm{~m}, 2 \mathrm{H}, \mathrm{OCH}_{2} \mathrm{CH}_{3}\right), 6.03\left(\mathrm{~s}, 2 \mathrm{H}, \mathrm{CH}_{2} \mathrm{Ph}\right), 7.26-7.36\left(\mathrm{~m}, 3 \mathrm{H}, \mathrm{C}_{3}, \mathrm{H}, \mathrm{C}_{4}{ }^{\prime} \mathrm{H}\right)$, 7.37-7.44 (m, 5H, $\left.\mathrm{C}_{3} \mathrm{H}, \mathrm{C}_{4} \mathrm{H}, \mathrm{C}_{2} \mathrm{H}\right), 7.76\left(\mathrm{dd}, 2 \mathrm{H},{ }^{3} J_{\mathrm{HH}}=7.4, J_{\mathrm{HH}}=2.2, \mathrm{C}_{2} \mathrm{H}\right) ; \delta[20]\left(\mathrm{CDCl}_{3}\right) 0.96(\mathrm{t}, 6 \mathrm{H}$, $J=7.2 \mathrm{~Hz}), 3.57-3.67$ (m, $2 \mathrm{H}), 3.81-3.91$ (m, $2 \mathrm{H}), 6.01(\mathrm{~s}, 2 \mathrm{H}), 7.30-7.40(\mathrm{~m}, 8 \mathrm{H}), 7.73-7.75$ (m, $2 \mathrm{H})$; ${ }^{13} \mathrm{C} \mathrm{NMR}\left(\mathrm{CDCl}_{3}\right) \delta 15.9\left(\mathrm{~d},{ }^{3} J_{\mathrm{CP}}=7.0, \mathrm{OCH}_{2} \mathrm{CH}_{3}\right), 54.2\left(\mathrm{CH}_{2} \mathrm{Ph}\right), 63.1\left(\mathrm{~d},{ }^{2} J_{\mathrm{CP}}=5.2, \mathrm{OCH}_{2} \mathrm{CH}_{3}\right), 121.6$ $\left(\mathrm{d},{ }^{1} J_{\mathrm{CP}}=217.5, \mathrm{P}(\mathrm{O}) \mathrm{C}=\right), 128.2\left(\mathrm{C}_{2}\right), 128.3\left(\mathrm{C}_{2^{\prime}}\right), 128.4\left(\mathrm{C}_{4^{\prime}}\right), 128.7\left(\mathrm{C}_{3^{\prime}}\right), 129.1\left(\mathrm{C}_{1}\right), 129.3\left(\mathrm{C}_{3}\right), 130.3$ $\left(\mathrm{C}_{4}\right), 135.9\left(\mathrm{C}_{1^{\prime}}\right), 153.6\left(\mathrm{~d},{ }^{2} J_{\mathrm{CP}}=19.0, \mathrm{PhC}=\right) ; \delta[20]\left(\mathrm{CDCl}_{3}\right)$ 14.8, 14.9, 53.2, 62.0, 62.1, 119.4, 121.6, $127.2,127.3,127.4,127.7,128.1,128.3,129.2,134.9,152.6 ;[\mathrm{M}+\mathrm{H}]^{+}$found $=372.1479, \mathrm{C}_{19} \mathrm{H}_{23} \mathrm{~N}_{3} \mathrm{O}_{3} \mathrm{P}$ requires 372.1477 .

Dipropyl (1-benzyl-4-phenyl-1,2,3-triazol-5-yl)phosphonate (13): yield: 43\% (0.17 g), colorless oil; ${ }^{31} \mathrm{P}$ $\operatorname{NMR}\left(\mathrm{CDCl}_{3}\right) \delta 4.6 ;{ }^{1} \mathrm{H} \mathrm{NMR}\left(\mathrm{CDCl}_{3}\right) \delta 0.68\left(\mathrm{t}, 6 \mathrm{H},{ }^{3} \mathrm{~J}_{\mathrm{HH}}=7.4, \mathrm{OCH}_{2} \mathrm{CH}_{2} \mathrm{CH}_{3}\right), 1.27-1.42(\mathrm{~m}, 4 \mathrm{H}$, $\left.\mathrm{OCH}_{2} \mathrm{CH}_{2} \mathrm{CH}_{3}\right), 3.42-3.60\left(\mathrm{~m}, 2 \mathrm{H}, \mathrm{OCH}_{2} \mathrm{CH}_{2} \mathrm{CH}_{3}\right), 3.70-3.84\left(\mathrm{~m}, 2 \mathrm{H}, \mathrm{OCH}_{2} \mathrm{CH}_{2} \mathrm{CH}_{3}\right), 6.04(\mathrm{~s}, 2 \mathrm{H}$, $\left.\mathrm{CH}_{2} \mathrm{Ph}\right), 7.25-7.35\left(\mathrm{~m}, 3 \mathrm{H}, \mathrm{C}_{3^{\prime}} \mathrm{H}, \mathrm{C}_{4}, \mathrm{H}\right), 7.35-7.45\left(\mathrm{~m}, 5 \mathrm{H}, \mathrm{C}_{3} \mathrm{H}, \mathrm{C}_{4} \mathrm{H}, \mathrm{C}_{2}, \mathrm{H}\right), 7.77\left(\mathrm{dd}, 2 \mathrm{H},{ }^{3} J_{\mathrm{HH}}=7.2\right.$, $\left.J_{\mathrm{HH}}=2.5, \mathrm{C}_{2} \mathrm{H}\right) ;{ }^{13} \mathrm{C} \mathrm{NMR}\left(\mathrm{CDCl}_{3}\right) \delta 9.9\left(\mathrm{OCH}_{2} \mathrm{CH}_{2} \mathrm{CH}_{3}\right), 23.4\left(\mathrm{~d},{ }^{3} J_{\mathrm{CP}}=7.1, \mathrm{OCH}_{2} \mathrm{CH}_{2} \mathrm{CH}_{3}\right), 54.2$ 
$\left(\mathrm{CH}_{2} \mathrm{Ph}\right), 68.4\left(\mathrm{~d},{ }^{2} J_{\mathrm{CP}}=5.6, \mathrm{OCH}_{2} \mathrm{CH}_{2} \mathrm{CH}_{3}\right), 121.6\left(\mathrm{~d},{ }^{1} J_{\mathrm{CP}}=217.9, \mathrm{P}(\mathrm{O}) \mathrm{C}=\right), 128.2\left(\mathrm{C}_{2}\right), 128.4\left(\mathrm{C}_{2^{\prime}}\right)$, $128.4\left(\mathrm{C}_{4^{\prime}}\right), 128.7\left(\mathrm{C}_{3^{\prime}}\right), 129.1\left(\mathrm{C}_{1}\right), 129.2\left(\mathrm{C}_{3}\right), 130.3\left(\mathrm{C}_{4}\right), 136.0\left(\mathrm{C}_{1^{\prime}}\right), 153.6\left(\mathrm{~d},{ }^{2} \mathrm{~J}_{\mathrm{CP}}=19.0, \mathrm{PhC}=\right) ;[\mathrm{M}+$ $\mathrm{H}]^{+}$found $=400.1778, \mathrm{C}_{21} \mathrm{H}_{27} \mathrm{~N}_{3} \mathrm{O}_{3} \mathrm{P}$ requires 400.1790 .

Diisopropyl (1-benzyl-4-phenyl-1,2,3-triazol-5-yl)phosphonate (14): yield: $40 \%(0.16 \mathrm{~g})$, colorless oil; ${ }^{31} \mathrm{P}$ $\operatorname{NMR}\left(\mathrm{CDCl}_{3}\right) \delta 2.0 ; \delta[20]\left(\mathrm{CDCl}_{3}\right) 2.19 ;{ }^{1} \mathrm{H} \mathrm{NMR}\left(\mathrm{CDCl}_{3}\right) \delta 0.83\left(\mathrm{~d}, 6 \mathrm{H},{ }^{3} J_{\mathrm{HH}}=6.2, \mathrm{OCH}\left(\mathrm{CH}_{3}\right)_{2}\right), 1.19$ $\left(\mathrm{d}, 6 \mathrm{H},{ }^{3} J_{\mathrm{HH}}=6.2, \mathrm{OCH}\left(\mathrm{CH}_{3}\right)_{2}\right), 4.23-4.44\left(\mathrm{~m}, 2 \mathrm{H}, \mathrm{OCH}\left(\mathrm{CH}_{3}\right)_{2}\right), 6.06\left(\mathrm{~s}, 2 \mathrm{H}, \mathrm{CH}_{2} \mathrm{Ph}\right), 7.24-7.35(\mathrm{~m}$, $\left.3 \mathrm{H}, \mathrm{C}_{3^{\prime}} \mathrm{H}, \mathrm{C}_{4^{\prime}} \mathrm{H}\right), 7.36-7.45\left(\mathrm{~m}, 5 \mathrm{H}, \mathrm{C}_{3} \mathrm{H}, \mathrm{C}_{4} \mathrm{H}, \mathrm{C}_{2^{\prime}} \mathrm{H}\right), 7.81\left(\mathrm{dd}, 2 \mathrm{H},{ }^{3} J_{\mathrm{HH}}=7.6, J_{\mathrm{HH}}=2.2, \mathrm{C}_{2} \mathrm{H}\right) ; \delta[20]$ $\left(\mathrm{CDCl}_{3}\right) 0.80(\mathrm{~d}, 6 \mathrm{H}, J=6.4 \mathrm{~Hz}), 1.17(\mathrm{~d}, 6 \mathrm{H}, J=6.0 \mathrm{~Hz}), 4.27-4.35(\mathrm{~m}, 2 \mathrm{H}), 6.05(\mathrm{~s}, 2 \mathrm{H}), 7.27-7.39(\mathrm{~m}, 8$ $\mathrm{H}), 7.79(\mathrm{~d}, 2 \mathrm{H}, J=5.6 \mathrm{~Hz}) ;{ }^{13} \mathrm{C} \mathrm{NMR}\left(\mathrm{CDCl}_{3}\right) \delta 23.2\left(\mathrm{~d},{ }^{3} J_{\mathrm{CP}}=5.6, \mathrm{OCH}\left(\mathrm{CH}_{3}\right)_{2}\right), 23.9\left(\mathrm{~d},{ }^{3} J_{\mathrm{CP}}=3.9\right.$, $\left.\mathrm{OCH}\left(\mathrm{CH}_{3}\right)_{2}\right), 54.2\left(\mathrm{CH}_{2} \mathrm{Ph}\right), 72.6\left(\mathrm{~d},{ }^{2} J_{\mathrm{CP}}=5.5, \mathrm{OCH}\left(\mathrm{CH}_{3}\right)_{2}\right), 122.6\left(\mathrm{~d},{ }^{1} J_{\mathrm{CP}}=218.6, \mathrm{P}(\mathrm{O}) \mathrm{C}=\right), 128.1\left(\mathrm{C}_{2}\right)$, $128.29\left(\mathrm{C}_{4^{\prime}}\right), 128.32\left(\mathrm{C}_{2^{\prime}}\right), 128.7\left(\mathrm{C}_{3^{\prime}}\right), 128.9\left(\mathrm{C}_{1}\right), 129.3\left(\mathrm{C}_{3}\right), 130.6\left(\mathrm{C}_{4}\right), 136.1\left(\mathrm{C}_{1^{\prime}}\right), 153.2\left(\mathrm{~d},{ }^{2} J_{\mathrm{CP}}=18.9\right.$, $\mathrm{PhC}=) ; \delta[20]\left(\mathrm{CDCl}_{3}\right)$ 22.1, 22.2, 22.8, 22.9, 53.1, 71.6, 120.5, 122.7, 127.1, 127.3, 127.6, 127.9, 128.3, 129.5, 135.1, 152.2; $[\mathrm{M}+\mathrm{H}]^{+}$found $=400.1777, \mathrm{C}_{21} \mathrm{H}_{27} \mathrm{~N}_{3} \mathrm{O}_{3} \mathrm{P}$ requires 400.1790 .

Dibutyl (1-benzyl-4-phenyl-1,2,3-triazol-5-yl)phosphonate (8): yield: $49 \%$ (0.20 g), colorless oil; ${ }^{31} \mathrm{P}$ NMR $\left(\mathrm{CDCl}_{3}\right) \delta 2.2 ;{ }^{1} \mathrm{H} \mathrm{NMR}\left(\mathrm{CDCl}_{3}\right) \delta 0.76\left(\mathrm{t}, 6 \mathrm{H},{ }^{3} \mathrm{~J}_{\mathrm{HH}}=7.3, \mathrm{OCH}_{2} \mathrm{CH}_{2} \mathrm{CH}_{2} \mathrm{CH}_{3}\right), 0.99-1.19(\mathrm{~m}, 4 \mathrm{H}$, $\left.\mathrm{OCH}_{2} \mathrm{CH}_{2} \mathrm{CH}_{2} \mathrm{CH}_{3}\right), 1.22-1.38\left(\mathrm{~m}, 4 \mathrm{H}, \mathrm{OCH}_{2} \mathrm{CH}_{2} \mathrm{CH}_{2} \mathrm{CH}_{3}\right), 3.46-3.62\left(\mathrm{~m}, 2 \mathrm{H}, \mathrm{OCH}_{2} \mathrm{CH}_{2} \mathrm{CH}_{2} \mathrm{CH}_{3}\right)$, 3.72-3.91 (m, 2H, $\left.\mathrm{OCH}_{2} \mathrm{CH}_{2} \mathrm{CH}_{2} \mathrm{CH}_{3}\right), 6.03\left(\mathrm{~s}, 2 \mathrm{H}, \mathrm{CH}_{2} \mathrm{Ph}\right), 7.25-7.34\left(\mathrm{~m}, 3 \mathrm{H}, \mathrm{C}_{3^{\prime}} \mathrm{H}, \mathrm{C}_{4}, \mathrm{H}\right), 7.36-7.43$ $\left(\mathrm{m}, 5 \mathrm{H}, \mathrm{C}_{3} \mathrm{H}, \mathrm{C}_{4} \mathrm{H}, \mathrm{C}_{2}, \mathrm{H}\right), 7.76\left(\mathrm{dd}, 2 \mathrm{H},{ }^{3} \mathrm{~J}_{\mathrm{HH}}=6.6, \mathrm{~J}_{\mathrm{HH}}=2.9, \mathrm{C}_{2} \mathrm{H}\right) ;{ }^{13} \mathrm{C}$ NMR $\left(\mathrm{CDCl}_{3}\right) \delta 13.5$ $\left(\mathrm{OCH}_{2} \mathrm{CH}_{2} \mathrm{CH}_{2} \mathrm{CH}_{3}\right), 18.5\left(\mathrm{OCH}_{2} \mathrm{CH}_{2} \mathrm{CH}_{2} \mathrm{CH}_{3}\right), 32.0\left(\mathrm{~d},{ }^{3} \mathrm{~J}_{\mathrm{CP}}=7.0, \mathrm{OCH}_{2} \mathrm{CH}_{2} \mathrm{CH}_{2} \mathrm{CH}_{3}\right), 54.2\left(\mathrm{CH}_{2} \mathrm{Ph}\right)$, $66.7\left(\mathrm{~d},{ }^{2} J_{\mathrm{CP}}=5.5, \mathrm{OCH}_{2} \mathrm{CH}_{2} \mathrm{CH}_{2} \mathrm{CH}_{3}\right), 121.6\left(\mathrm{~d},{ }^{1} J_{\mathrm{CP}}=217.8, \mathrm{P}(\mathrm{O}) \mathrm{C}=\right), 128.2\left(\mathrm{C}_{2}\right), 128.3\left(\mathrm{C}_{2^{\prime}}\right), 128.4$ $\left(\mathrm{C}_{4^{\prime}}\right), 128.7\left(\mathrm{C}_{3^{\prime}}\right), 129.1\left(\mathrm{C}_{1}\right), 129.3\left(\mathrm{C}_{3}\right), 130.4\left(\mathrm{C}_{4}\right), 136.0\left(\mathrm{C}_{1^{\prime}}\right), 153.6\left(\mathrm{~d},{ }^{2} J_{\mathrm{CP}}=19.1, \mathrm{PhC}=\right)$; $[\mathrm{M}+$ $\mathrm{H}]^{+}$found $=428.2086, \mathrm{C}_{23} \mathrm{H}_{31} \mathrm{~N}_{3} \mathrm{O}_{3}$ P requires 428.2103.

Dipentyl (1-benzyl-4-phenyl-1,2,3-triazol-5-yl)phosphonate (15): yield: $34 \%(0.15 \mathrm{~g})$, colorless oil; ${ }^{31} \mathrm{P}$ NMR $\left(\mathrm{CDCl}_{3}\right) \delta 2.4 ;{ }^{1} \mathrm{H}$ NMR $\left(\mathrm{CDCl}_{3}\right) \delta 0.80\left(\mathrm{t}, 6 \mathrm{H},{ }^{3} \mathrm{~J}_{\mathrm{HH}}=7.1, \mathrm{OCH}_{2} \mathrm{CH}_{2} \mathrm{CH}_{2} \mathrm{CH}_{2} \mathrm{CH}_{3}\right), 1.00-1.13$ (m, $\left.4 \mathrm{H}, \mathrm{OCH}_{2} \mathrm{CH}_{2} \mathrm{CH}_{2} \mathrm{CH}_{2} \mathrm{CH}_{3}\right), 1.13-1.25\left(\mathrm{~m}, 4 \mathrm{H}, \mathrm{OCH}_{2} \mathrm{CH}_{2} \mathrm{CH}_{2} \mathrm{CH}_{2} \mathrm{CH}_{3}\right), 1.25-1.40(\mathrm{~m}, 4 \mathrm{H}$, $\left.\mathrm{OCH}_{2} \mathrm{CH}_{2} \mathrm{CH}_{2} \mathrm{CH}_{2} \mathrm{CH}_{3}\right), 3.47-3.62\left(\mathrm{~m}, 2 \mathrm{H}, \mathrm{OCH}_{2} \mathrm{CH}_{2} \mathrm{CH}_{2} \mathrm{CH}_{3}\right), 3.74-3.89\left(\mathrm{~m}, 2 \mathrm{H}, \mathrm{OCH}_{2} \mathrm{CH}_{2} \mathrm{CH}_{2} \mathrm{CH}_{3}\right)$, $6.03\left(\mathrm{~s}, 2 \mathrm{H}, \mathrm{CH}_{2} \mathrm{Ph}\right), 7.27-7.37\left(\mathrm{~m}, 3 \mathrm{H}, \mathrm{C}_{3^{\prime}} \mathrm{H}, \mathrm{C}_{4^{\prime}} \mathrm{H}\right), 7.37-7.47\left(\mathrm{~m}, 5 \mathrm{H}, \mathrm{C}_{3} \mathrm{H}, \mathrm{C}_{4} \mathrm{H}, \mathrm{C}_{2}, \mathrm{H}\right), 7.76$ $\left(\mathrm{dd}, 2 \mathrm{H},{ }^{3} J_{\mathrm{HH}}=6.6, J_{\mathrm{HH}}=3.0, \mathrm{C}_{2} \mathrm{H}\right) ;{ }^{13} \mathrm{C} \mathrm{NMR}\left(\mathrm{CDCl}_{3}\right) \delta 14.0\left(\mathrm{OCH}_{2} \mathrm{CH}_{2} \mathrm{CH}_{2} \mathrm{CH}_{2} \mathrm{CH}_{3}\right), 22.2$ $\left(\mathrm{OCH}_{2} \mathrm{CH}_{2} \mathrm{CH}_{2} \mathrm{CH}_{2} \mathrm{CH}_{3}\right), 27.4\left(\mathrm{OCH}_{2} \mathrm{CH}_{2} \mathrm{CH}_{2} \mathrm{CH}_{2} \mathrm{CH}_{3}\right), 29.7\left(\mathrm{~d},{ }^{3} J_{\mathrm{CP}}=7.1, \mathrm{OCH}_{2} \mathrm{CH}_{2} \mathrm{CH}_{2} \mathrm{CH}_{2} \mathrm{CH}_{3}\right)$, $54.2\left(\mathrm{CH}_{2} \mathrm{Ph}\right), 67.0\left(\mathrm{~d},{ }^{2} J_{\mathrm{CP}}=5.5, \mathrm{OCH}_{2} \mathrm{CH}_{2} \mathrm{CH}_{2} \mathrm{CH}_{2} \mathrm{CH}_{3}\right), 121.6\left(\mathrm{~d},{ }^{1} J_{\mathrm{CP}}=217.8, \mathrm{P}(\mathrm{O}) \mathrm{C}=\right), 128.2\left(\mathrm{C}_{2}\right)$, $128.3\left(\mathrm{C}_{2^{\prime}}\right), 128.4\left(\mathrm{C}_{4^{\prime}}\right), 128.7\left(\mathrm{C}_{3^{\prime}}\right), 129.1\left(\mathrm{C}_{1}\right), 129.3\left(\mathrm{C}_{3}\right), 130.3\left(\mathrm{C}_{4}\right), 136.0\left(\mathrm{C}_{1^{\prime}}\right), 153.6\left(\mathrm{~d},{ }^{2} J_{\mathrm{CP}}=19.1\right.$, $\mathrm{PhC}=) ;[\mathrm{M}+\mathrm{H}]^{+}$found $=456.2398, \mathrm{C}_{25} \mathrm{H}_{35} \mathrm{~N}_{3} \mathrm{O}_{3} \mathrm{P}$ requires 456.2416 .

Dimethyl [1-(4-methylbenzyl)-4-phenyl-1,2,3-triazol-5-yl]phosphonate (16): yield: 40\% (0.14 g), colorless oil; ${ }^{31} \mathrm{P} \mathrm{NMR}\left(\mathrm{CDCl}_{3}\right) \delta 7.5 ;{ }^{1} \mathrm{H}$ NMR $\left(\mathrm{CDCl}_{3}\right) \delta 2.32\left(\mathrm{~s}, 3 \mathrm{H}, \mathrm{PhCH}_{3}\right), 3.43\left(\mathrm{~d}, 6 \mathrm{H},{ }^{3} J_{\mathrm{HP}}=11.7, \mathrm{OCH}_{3}\right), 5.96(\mathrm{~s}$, $\left.2 \mathrm{H}, \mathrm{CH}_{2} \mathrm{Ph}\right), 7.15\left(\mathrm{~d}, 2 \mathrm{H},{ }^{3} J_{\mathrm{HH}}=7.8, \mathrm{C}_{3^{\prime}} \mathrm{H}\right), 7.30\left(\mathrm{~d}, 2 \mathrm{H},{ }^{3} \mathrm{~J}_{\mathrm{HH}}=7.9, \mathrm{C}_{2}, \mathrm{H}\right), 7.40-7.44\left(\mathrm{~m}, 3 \mathrm{H}, \mathrm{C}_{3} \mathrm{H}, \mathrm{C}_{4} \mathrm{H}\right)$, $7.73\left(\mathrm{dd}, 2 \mathrm{H},{ }^{3} J_{\mathrm{HH}}=7.3, J_{\mathrm{HH}}=2.4, \mathrm{C}_{2} \mathrm{H}\right) ;{ }^{13} \mathrm{C} \mathrm{NMR}\left(\mathrm{CDCl}_{3}\right) \delta 21.3\left(\mathrm{CH}_{3} \mathrm{Ph}\right), 53.0\left(\mathrm{~d},{ }^{2} J_{\mathrm{CP}}=5.3, \mathrm{OCH}_{3}\right)$, $54.1\left(\mathrm{CH}_{2} \mathrm{Ph}\right), 120.4\left(\mathrm{~d},{ }^{1} J_{\mathrm{CP}}=219.5, \mathrm{P}(\mathrm{O}) \mathrm{C}=\right), 128.3\left(\mathrm{C}_{2}, \mathrm{C}_{2^{\prime}}\right), 129.15\left(\mathrm{C}_{3^{\prime}}\right), 129.17\left(\mathrm{C}_{1}\right), 129.4\left(\mathrm{C}_{3}\right), 130.1$ $\left(\mathrm{C}_{4}\right), 132.8\left(\mathrm{C}_{1^{\prime}}\right), 138.3\left(\mathrm{C}_{4^{\prime}}\right), 153.8\left(\mathrm{~d},{ }^{2} J_{\mathrm{CP}}=19.4, \mathrm{PhC}=\right)$; $[\mathrm{M}+\mathrm{H}]^{+}$found $=358.1315, \mathrm{C}_{18} \mathrm{H}_{21} \mathrm{~N}_{3} \mathrm{O}_{3} \mathrm{P}$ requires 358.1315 .

Diethyl [1-(4-methylbenzyl)-4-phenyl-1,2,3-triazol-5-yl]phosphonate (17): yield: 52\% (0.20 g), colorless oil; ${ }^{31} \mathrm{P} \mathrm{NMR}\left(\mathrm{CDCl}_{3}\right) \delta 4.3 ;{ }^{1} \mathrm{H}$ NMR $\left(\mathrm{CDCl}_{3}\right) \delta 0.99\left(\mathrm{t}, 6 \mathrm{H},{ }^{3} J_{\mathrm{HH}}=7.0, \mathrm{OCH}_{2} \mathrm{CH}_{3}\right), 2.32\left(\mathrm{~s}, 3 \mathrm{H}, \mathrm{PhCH}_{3}\right)$, 3.58-3.72 (m, 2H, OCH $\left.{ }_{2} \mathrm{CH}_{3}\right), 3.85-3.95\left(\mathrm{~m}, 2 \mathrm{H}, \mathrm{OCH}_{2} \mathrm{CH}_{3}\right), 6.00\left(\mathrm{~s}, 2 \mathrm{H}, \mathrm{CH}_{2} \mathrm{Ph}\right), 7.14\left(\mathrm{~d}, 2 \mathrm{H},{ }^{3} \mathrm{~J}_{\mathrm{HH}}=7.8\right.$, $\left.\mathrm{C}_{3^{\prime}} \mathrm{H}\right), 7.30\left(\mathrm{~d}, 2 \mathrm{H},{ }^{3} \mathrm{~J}_{\mathrm{HH}}=8.0, \mathrm{C}_{2}, \mathrm{H}\right), 7.38-7.44\left(\mathrm{~m}, 3 \mathrm{H}, \mathrm{C}_{3} \mathrm{H}, \mathrm{C}_{4} \mathrm{H}\right), 7.74\left(\mathrm{dd}, 2 \mathrm{H},{ }^{3} J_{\mathrm{HH}}=7.7, J_{\mathrm{HH}}=2.0\right.$, $\left.\mathrm{C}_{2} \mathrm{H}\right) ;{ }^{13} \mathrm{C} \mathrm{NMR}\left(\mathrm{CDCl}_{3}\right) \delta 15.9\left(\mathrm{~d},{ }^{3} J_{\mathrm{CP}}=7.0, \mathrm{OCH}_{2} \mathrm{CH}_{3}\right), 21.2\left(\mathrm{CH}_{3} \mathrm{Ph}\right), 54.0\left(\mathrm{CH}_{2} \mathrm{Ph}\right), 63.1\left(\mathrm{~d},{ }^{2} J_{\mathrm{CP}}=5.1\right.$, $\left.\mathrm{OCH}_{2} \mathrm{CH}_{3}\right), 121.5\left(\mathrm{~d},{ }^{1} J_{\mathrm{CP}}=217.7, \mathrm{P}(\mathrm{O}) \mathrm{C}=\right), 128.2\left(\mathrm{C}_{2}\right), 128.3\left(\mathrm{C}_{2^{\prime}}\right), 129.0\left(\mathrm{C}_{1}\right), 129.3\left(\mathrm{C}_{3^{\prime}}\right), 129.4\left(\mathrm{C}_{3}\right)$, 
$130.4\left(\mathrm{C}_{4}\right), 132.9\left(\mathrm{C}_{1^{\prime}}\right), 138.2\left(\mathrm{C}_{4^{\prime}}\right), 153.5\left(\mathrm{~d},{ }^{2} J_{\mathrm{CP}}=19.1, \mathrm{PhC}=\right) ;[\mathrm{M}+\mathrm{H}]^{+}$found $=386.1633, \mathrm{C}_{20} \mathrm{H}_{25} \mathrm{~N}_{3} \mathrm{O}_{3} \mathrm{P}$ requires 386.1628 .

Dibutyl [1-(4-methylbenzyl)-4-phenyl-1,2,3-triazol-5-yl]phosphonate (18): yield: 42\% (0.19 g), colorless oil; ${ }^{31} \mathrm{P} \mathrm{NMR}\left(\mathrm{CDCl}_{3}\right) \delta 3.1 ;{ }^{1} \mathrm{H}$ NMR $\left(\mathrm{CDCl}_{3}\right) \delta 0.69\left(\mathrm{t}, 6 \mathrm{H},{ }^{3} J_{\mathrm{HH}}=7.3, \mathrm{OCH}_{2} \mathrm{CH}_{2} \mathrm{CH}_{2} \mathrm{CH}_{3}\right), 0.93-1.10(\mathrm{~m}$, $\left.4 \mathrm{H}, \mathrm{OCH}_{2} \mathrm{CH}_{2} \mathrm{CH}_{2} \mathrm{CH}_{3}\right), 1.11-1.13\left(\mathrm{~m}, 4 \mathrm{H}, \mathrm{OCH}_{2} \mathrm{CH}_{2} \mathrm{CH}_{2} \mathrm{CH}_{3}\right), 2.25\left(\mathrm{~s}, 3 \mathrm{H}, \mathrm{PhCH}_{3}\right), 3.41-3.57(\mathrm{~m}, 2 \mathrm{H}$, $\left.\mathrm{OCH}_{2} \mathrm{CH}_{2} \mathrm{CH}_{2} \mathrm{CH}_{3}\right), 3.67-3.83\left(\mathrm{~m}, 2 \mathrm{H}, \mathrm{OCH}_{2} \mathrm{CH}_{2} \mathrm{CH}_{2} \mathrm{CH}_{3}\right), 5.91\left(\mathrm{~s}, 2 \mathrm{H}, \mathrm{CH}_{2} \mathrm{Ph}\right), 7.06\left(\mathrm{~d}, 2 \mathrm{H},{ }^{3} J_{\mathrm{HH}}=7.8\right.$, $\left.\mathrm{C}_{3^{\prime}} \mathrm{H}\right), 7.22\left(\mathrm{~d}, 2 \mathrm{H},{ }^{3} J_{\mathrm{HH}}=7.7, \mathrm{C}_{2}, \mathrm{H}\right), 7.27-7.38\left(\mathrm{~m}, 3 \mathrm{H}, \mathrm{C}_{3} \mathrm{H}, \mathrm{C}_{4} \mathrm{H}\right), 7.67\left(\mathrm{dd}, 2 \mathrm{H},{ }^{3} J_{\mathrm{HH}}=6.6, J_{\mathrm{HH}}=3.0\right.$, $\left.\mathrm{C}_{2} \mathrm{H}\right) ;{ }^{13} \mathrm{C} \mathrm{NMR}\left(\mathrm{CDCl}_{3}\right) \delta 13.6\left(\mathrm{OCH}_{2} \mathrm{CH}_{2} \mathrm{CH}_{2} \mathrm{CH}_{3}\right), 18.5\left(\mathrm{OCH}_{2} \mathrm{CH}_{2} \mathrm{CH}_{2} \mathrm{CH}_{3}\right), 21.3\left(\mathrm{CH}_{3} \mathrm{Ph}\right), 32.0$ $\left(\mathrm{d},{ }^{3} J_{\mathrm{CP}}=7.1, \mathrm{OCH}_{2} \mathrm{CH}_{2} \mathrm{CH}_{2} \mathrm{CH}_{3}\right), 54.1\left(\mathrm{CH}_{2} \mathrm{Ph}\right), 66.7\left(\mathrm{~d},{ }^{2} J_{\mathrm{CP}}=5.5, \mathrm{OCH}_{2} \mathrm{CH}_{2} \mathrm{CH}_{2} \mathrm{CH}_{3}\right), 121.5(\mathrm{~d}$, $\left.{ }^{1} J_{\mathrm{CP}}=218.5, \mathrm{P}(\mathrm{O}) \mathrm{C}=\right), 128.2\left(\mathrm{C}_{2}\right), 128.4\left(\mathrm{C}_{2^{\prime}}\right), 129.0\left(\mathrm{C}_{1}\right), 129.3\left(\mathrm{C}_{3^{\prime}}\right), 129.4\left(\mathrm{C}_{3}\right), 130.4\left(\mathrm{C}_{4}\right), 133.1\left(\mathrm{C}_{1^{\prime}}\right)$, $138.2\left(\mathrm{C}_{4^{\prime}}\right), 153.5\left(\mathrm{~d},{ }^{2} J_{\mathrm{CP}}=19.3, \mathrm{PhC}=\right) ;[\mathrm{M}+\mathrm{H}]^{+}$found $=442.2242, \mathrm{C}_{24} \mathrm{H}_{33} \mathrm{~N}_{3} \mathrm{O}_{3} \mathrm{P}$ requires 442.2260.

Dibutyl [1-(2-fluorobenzyl)-4-phenyl-1,2,3-triazol-5-yl]phosphonate (19): yield: 30\% (0.13 g), pale yellow oil; ${ }^{31} \mathrm{P} \mathrm{NMR}\left(\mathrm{CDCl}_{3}\right) \delta 4.6 ;{ }^{1} \mathrm{H}$ NMR $\left(\mathrm{CDCl}_{3}\right) \delta 0.79\left(\mathrm{t}, 6 \mathrm{H},{ }^{3} \mathrm{~J}_{\mathrm{HH}}=7.3, \mathrm{OCH}_{2} \mathrm{CH}_{2} \mathrm{CH}_{2} \mathrm{CH}_{3}\right), 1.07-1.22(\mathrm{~m}$, $\left.4 \mathrm{H}, \mathrm{OCH}_{2} \mathrm{CH}_{2} \mathrm{CH}_{2} \mathrm{CH}_{3}\right), 1.29-1.42\left(\mathrm{~m}, 4 \mathrm{H}, \mathrm{OCH}_{2} \mathrm{CH}_{2} \mathrm{CH}_{2} \mathrm{CH}_{3}\right), 3.59-3.76\left(\mathrm{~m}, 2 \mathrm{H}, \mathrm{OCH}_{2} \mathrm{CH}_{2} \mathrm{CH}_{2} \mathrm{CH}_{3}\right)$, 3.83-3.99 (m, 2H, OCH $\left.{ }_{2} \mathrm{CH}_{2} \mathrm{CH}_{2} \mathrm{CH}_{3}\right), 6.10\left(\mathrm{~s}, 2 \mathrm{H}, \mathrm{CH}_{2} \mathrm{Ph}\right), 7.03-7.15\left(\mathrm{~m}, 3 \mathrm{H}, \mathrm{C}_{3^{\prime}} \mathrm{H}, \mathrm{C}_{5^{\prime}} \mathrm{H}, \mathrm{C}_{6^{\prime}} \mathrm{H}\right)$, 7.24-7.35 (m, 1H, $\left.\mathrm{C}_{4}, \mathrm{H}\right), 7.38-7.47\left(\mathrm{~m}, 3 \mathrm{H}, \mathrm{C}_{3} \mathrm{H}, \mathrm{C}_{4} \mathrm{H}\right), 7.79\left(\mathrm{dd}, 2 \mathrm{H},{ }^{3} J_{\mathrm{HH}}=7.2, J_{\mathrm{HH}}=2.6, \mathrm{C}_{2} \mathrm{H}\right) ;{ }^{13} \mathrm{C} \mathrm{NMR}$ $\left(\mathrm{CDCl}_{3}\right) \delta 13.5\left(\mathrm{OCH}_{2} \mathrm{CH}_{2} \mathrm{CH}_{2} \mathrm{CH}_{3}\right), 18.6\left(\mathrm{OCH}_{2} \mathrm{CH}_{2} \mathrm{CH}_{2} \mathrm{CH}_{3}\right), 32.0\left(\mathrm{~d},{ }^{3} J_{\mathrm{CP}}=6.9, \mathrm{OCH}_{2} \mathrm{CH}_{2} \mathrm{CH}_{2} \mathrm{CH}_{3}\right)$, $48.2\left(\mathrm{~d},{ }^{3} J_{\mathrm{CP}}=4.7, \mathrm{CH}_{2} \mathrm{Ph}\right), 66.8\left(\mathrm{~d},{ }^{2} J_{\mathrm{CP}}=5.7, \mathrm{OCH}_{2} \mathrm{CH}_{2} \mathrm{CH}_{2} \mathrm{CH}_{3}\right), 115.7\left(\mathrm{~d},{ }^{2} J_{\mathrm{CF}}=21.1, \mathrm{C}_{3^{\prime}}\right), 122.1(\mathrm{~d}$, $\left.{ }^{1} J_{\mathrm{CP}}=218.6, \mathrm{P}(\mathrm{O}) \mathrm{C}=\right), 123.4\left(\mathrm{~d},{ }^{2} J_{\mathrm{CF}}=14.3, \mathrm{C}_{1^{\prime}}\right), 124.4\left(\mathrm{~d},{ }^{2} J_{\mathrm{CF}}=3.7, \mathrm{C}_{5^{\prime}}\right), 128.2\left(\mathrm{C}_{2}\right), 129.1\left(\mathrm{C}_{1}\right), 129.3$ $\left(\mathrm{C}_{3}\right), 129.4\left(\mathrm{~d},{ }^{3} J_{\mathrm{CF}}=3.2, \mathrm{C}_{4^{\prime}}\right), 130.1\left(\mathrm{~d},{ }^{3} J_{\mathrm{CF}}=8.1, \mathrm{C}_{6^{\prime}}\right), 130.2\left(\mathrm{C}_{4}\right), 153.5\left(\mathrm{~d},{ }^{2} J_{\mathrm{CP}}=19.2, \mathrm{PhC}=\right), 160.4(\mathrm{~d}$, $\left.{ }^{1} J_{\mathrm{CF}}=248.8, \mathrm{C}_{2^{\prime}}\right) ;[\mathrm{M}+\mathrm{H}]^{+}$found $=446.1975, \mathrm{C}_{23} \mathrm{H}_{30} \mathrm{~N}_{3} \mathrm{O}_{3}$ FP requires 446.2008.

Dibutyl [1-(3-fluorobenzyl)-4-phenyl-1,2,3-triazol-5-yl]phosphonate (20): yield: 34\% (0.15 g), pale yellow oil; ${ }^{31} \mathrm{P} \mathrm{NMR}\left(\mathrm{CDCl}_{3}\right) \delta 2.1 ;{ }^{1} \mathrm{H}$ NMR $\left(\mathrm{CDCl}_{3}\right) \delta 0.77\left(\mathrm{t}, 6 \mathrm{H},{ }^{3} J_{\mathrm{HH}}=7.3, \mathrm{OCH}_{2} \mathrm{CH}_{2} \mathrm{CH}_{2} \mathrm{CH}_{3}\right), 1.03-1.22(\mathrm{~m}$, $\left.4 \mathrm{H}, \mathrm{OCH}_{2} \mathrm{CH}_{2} \mathrm{CH}_{2} \mathrm{CH}_{3}\right), 1.22-1.42\left(\mathrm{~m}, 4 \mathrm{H}, \mathrm{OCH}_{2} \mathrm{CH}_{2} \mathrm{CH}_{2} \mathrm{CH}_{3}\right), 3.53-3.69\left(\mathrm{~m}, 2 \mathrm{H}, \mathrm{OCH}_{2} \mathrm{CH}_{2} \mathrm{CH}_{2} \mathrm{CH}_{3}\right)$, 3.81-3.94 (m, 2H, OCH $\left.{ }_{2} \mathrm{CH}_{2} \mathrm{CH}_{2} \mathrm{CH}_{3}\right), 6.03\left(\mathrm{~s}, 2 \mathrm{H}, \mathrm{CH}_{2} \mathrm{Ph}\right), 6.95-7.05\left(\mathrm{~m}, 1 \mathrm{H}, \mathrm{C}_{4}, \mathrm{H}\right), 7.06-7.22(\mathrm{~m}, 2 \mathrm{H}$, $\left.\mathrm{C}_{2}, \mathrm{H}, \mathrm{C}_{6}, \mathrm{H}\right), 7.25-7.34\left(\mathrm{~m}, 1 \mathrm{H}, \mathrm{C}_{5}, \mathrm{H}\right), 7.36-7.47\left(\mathrm{~m}, 3 \mathrm{H}, \mathrm{C}_{3} \mathrm{H}, \mathrm{C}_{4} \mathrm{H}\right), 7.76\left(\mathrm{dd}, 2 \mathrm{H},{ }^{3} J_{\mathrm{HH}}=6.4, J_{\mathrm{HH}}=3.4\right.$, $\left.\mathrm{C}_{2} \mathrm{H}\right) ;{ }^{13} \mathrm{C}$ NMR $\left(\mathrm{CDCl}_{3}\right) \delta 13.5\left(\mathrm{OCH}_{2} \mathrm{CH}_{2} \mathrm{CH}_{2} \mathrm{CH}_{3}\right), 18.5\left(\mathrm{OCH}_{2} \mathrm{CH}_{2} \mathrm{CH}_{2} \mathrm{CH}_{3}\right), 32.0\left(\mathrm{~d},{ }^{3} J_{\mathrm{CP}}=7.0\right.$, $\left.\mathrm{OCH}_{2} \mathrm{CH}_{2} \mathrm{CH}_{2} \mathrm{CH}_{3}\right), 53.5\left(\mathrm{CH}_{2} \mathrm{Ph}\right), 66.8\left(\mathrm{~d},{ }^{2} J_{\mathrm{CP}}=5.6, \mathrm{OCH}_{2} \mathrm{CH}_{2} \mathrm{CH}_{2} \mathrm{CH}_{3}\right), 115.3\left(\mathrm{~d},{ }^{2} J_{\mathrm{CF}}=21.8, \mathrm{C}_{2}\right.$, $\left.\mathrm{C}_{4^{\prime}}\right), 121.6\left(\mathrm{~d},{ }^{1} J_{\mathrm{CP}}=218.0, \mathrm{P}(\mathrm{O}) \mathrm{C}=\right), 124.0\left(\mathrm{~d}, J_{\mathrm{CF}}=3.1, \mathrm{C}_{6^{\prime}}\right), 128.2\left(\mathrm{C}_{2}\right), 129.1\left(\mathrm{C}_{1}\right), 129.2\left(\mathrm{C}_{3}\right), 130.2\left(\mathrm{C}_{4}\right)$, $130.3\left(\mathrm{~d},{ }^{3} J_{\mathrm{CF}}=8.1, \mathrm{C}_{5^{\prime}}\right), 138.3\left(\mathrm{~d},{ }^{3} J_{\mathrm{CF}}=7.5, \mathrm{C}_{1^{\prime}}\right), 153.5\left(\mathrm{~d},{ }^{2} J_{\mathrm{CP}}=18.9, \mathrm{PhC}=\right), 162.3\left(\mathrm{~d},{ }^{1} J_{\mathrm{CF}}=247.0\right.$, $\left.\mathrm{C}_{3^{\prime}}\right) ;[\mathrm{M}+\mathrm{H}]^{+}$found $=446.1969, \mathrm{C}_{23} \mathrm{H}_{30} \mathrm{~N}_{3} \mathrm{O}_{3} \mathrm{FP}$ requires 446.2008 .

Dibutyl [1-(4-fluorobenzyl)-4-phenyl-1,2,3-triazol-5-yl]phosphonate (21): yield: 36\% (0.16 g), pale yellow oil; ${ }^{31} \mathrm{P} \mathrm{NMR}\left(\mathrm{CDCl}_{3}\right) \delta 2.3 ;{ }^{1} \mathrm{H}$ NMR $\left(\mathrm{CDCl}_{3}\right) \delta 0.77\left(\mathrm{t}, 6 \mathrm{H},{ }^{3} \mathrm{~J}_{\mathrm{HH}}=7.3, \mathrm{OCH}_{2} \mathrm{CH}_{2} \mathrm{CH}_{2} \mathrm{CH}_{3}\right), 1.04-1.19(\mathrm{~m}$, $\left.4 \mathrm{H}, \mathrm{OCH}_{2} \mathrm{CH}_{2} \mathrm{CH}_{2} \mathrm{CH}_{3}\right), 1.22-1.41\left(\mathrm{~m}, 4 \mathrm{H}, \mathrm{OCH}_{2} \mathrm{CH}_{2} \mathrm{CH}_{2} \mathrm{CH}_{3}\right), 3.49-3.68\left(\mathrm{~m}, 2 \mathrm{H}, \mathrm{OCH}_{2} \mathrm{CH}_{2} \mathrm{CH}_{2} \mathrm{CH}_{3}\right)$, $3.77-3.96\left(\mathrm{~m}, 2 \mathrm{H}, \mathrm{OCH}_{2} \mathrm{CH}_{2} \mathrm{CH}_{2} \mathrm{CH}_{3}\right), 6.00\left(\mathrm{~s}, 2 \mathrm{H}, \mathrm{CH}_{2} \mathrm{Ph}\right), 7.03\left(\mathrm{t}, 2 \mathrm{H},{ }^{3} J_{\mathrm{HH}}={ }^{3} J_{\mathrm{HF}}=8.7, \mathrm{C}_{2}, \mathrm{H}\right)$, 7.34-7.47 (m, 5H, $\left.\mathrm{C}_{3} \mathrm{H}, \mathrm{C}_{4} \mathrm{H}, \mathrm{C}_{3}, \mathrm{H}\right), 7.75\left(\mathrm{dd}, 2 \mathrm{H},{ }^{3} \mathrm{~J}_{\mathrm{HH}}=6.7, \mathrm{~J}_{\mathrm{HH}}=3.0, \mathrm{C}_{2} \mathrm{H}\right) ;{ }^{13} \mathrm{C} \mathrm{NMR}\left(\mathrm{CDCl}_{3}\right) \delta$ $13.5\left(\mathrm{OCH}_{2} \mathrm{CH}_{2} \mathrm{CH}_{2} \mathrm{CH}_{3}\right), 18.5\left(\mathrm{OCH}_{2} \mathrm{CH}_{2} \mathrm{CH}_{2} \mathrm{CH}_{3}\right), 32.0\left(\mathrm{~d},{ }^{3} J_{\mathrm{CP}}=7.0, \mathrm{OCH}_{2} \mathrm{CH}_{2} \mathrm{CH}_{2} \mathrm{CH}_{3}\right), 53.4$ $\left(\mathrm{CH}_{2} \mathrm{Ph}\right), 66.7\left(\mathrm{~d},{ }^{2} J_{\mathrm{CP}}=5.6, \mathrm{OCH}_{2} \mathrm{CH}_{2} \mathrm{CH}_{2} \mathrm{CH}_{3}\right), 115.6\left(\mathrm{~d},{ }^{2} J_{\mathrm{CF}}=21.7, \mathrm{C}_{3^{\prime}}\right), 121.4\left(\mathrm{~d},{ }^{1} J_{\mathrm{CP}}=218.0\right.$, $\mathrm{P}(\mathrm{O}) \mathrm{C}=), 128.2\left(\mathrm{C}_{2}\right), 129.1\left(\mathrm{C}_{1}\right), 129.2\left(\mathrm{C}_{3}\right), 130.4\left(\mathrm{~d},{ }^{3} J_{\mathrm{CF}}=8.3, \mathrm{C}_{2^{\prime}}\right), 130.2\left(\mathrm{C}_{4}\right), 131.7\left(\mathrm{~d}, J_{\mathrm{CF}}=3.1, \mathrm{C}_{1^{\prime}}\right)$, $153.5\left(\mathrm{~d},{ }^{2} J_{\mathrm{CP}}=19.0, \mathrm{PhC}=\right), 162.8\left(\mathrm{~d},{ }^{1} J_{\mathrm{CF}}=247.4, \mathrm{C}_{4^{\prime}}\right) ;[\mathrm{M}+\mathrm{H}]^{+}$found $=446.1972, \mathrm{C}_{23} \mathrm{H}_{30} \mathrm{~N}_{3} \mathrm{O}_{3} \mathrm{FP}$ requires 446.2008 .

Dibutyl [1-(4-trifluoromethyl)-4-phenyl-1,2,3-triazol-5-yl]phosphonate (22): yield: 39\% (0.19 g), pale yellow oil ${ }^{31}{ }^{\mathrm{P} N M R}\left(\mathrm{CDCl}_{3}\right) \delta 2.0 ;{ }^{1} \mathrm{H} \mathrm{NMR}\left(\mathrm{CDCl}_{3}\right) \delta 0.76\left(\mathrm{t}, 6 \mathrm{H},{ }^{3} \mathrm{~J}_{\mathrm{HH}}=7.3, \mathrm{OCH}_{2} \mathrm{CH}_{2} \mathrm{CH}_{2} \mathrm{CH}_{3}\right), 0.97-1.18(\mathrm{~m}$, $\left.4 \mathrm{H}, \mathrm{OCH}_{2} \mathrm{CH}_{2} \mathrm{CH}_{2} \mathrm{CH}_{3}\right), 1.20-1.40\left(\mathrm{~m}, 4 \mathrm{H}, \mathrm{OCH}_{2} \mathrm{CH}_{2} \mathrm{CH}_{2} \mathrm{CH}_{3}\right), 3.53-3.67\left(\mathrm{~m}, 2 \mathrm{H}, \mathrm{OCH}_{2} \mathrm{CH}_{2} \mathrm{CH}_{2} \mathrm{CH}_{3}\right)$, 3.77-3.95 (m, 2H, $\left.\mathrm{OCH}_{2} \mathrm{CH}_{2} \mathrm{CH}_{2} \mathrm{CH}_{3}\right), 6.10\left(\mathrm{~s}, 2 \mathrm{H}, \mathrm{CH}_{2} \mathrm{Ph}\right), 7.37-7.46\left(\mathrm{~m}, 3 \mathrm{H}, \mathrm{C}_{3} \mathrm{H}, \mathrm{C}_{4} \mathrm{H}\right), 7.51$ $\left(\mathrm{d}, 2 \mathrm{H},{ }^{3} J_{\mathrm{HH}}=8.0, \mathrm{C}_{2}, \mathrm{H}\right), 7.61\left(\mathrm{~d}, 2 \mathrm{H},{ }^{3} J_{\mathrm{HH}}=8.1, \mathrm{C}_{3^{\prime}} \mathrm{H}\right), 7.76\left(\mathrm{dd}, 2 \mathrm{H},{ }^{3} J_{\mathrm{HH}}=6.8, J_{\mathrm{HH}}=2.9\right.$, 
$\left.\mathrm{C}_{2} \mathrm{H}\right) ;{ }^{13} \mathrm{C} \mathrm{NMR}\left(\mathrm{CDCl}_{3}\right) \delta 13.4\left(\mathrm{OCH}_{2} \mathrm{CH}_{2} \mathrm{CH}_{2} \mathrm{CH}_{3}\right), 18.5\left(\mathrm{OCH}_{2} \mathrm{CH}_{2} \mathrm{CH}_{2} \mathrm{CH}_{3}\right), 31.9\left(\mathrm{~d},{ }^{3} J_{\mathrm{CP}}=7.0\right.$, $\left.\mathrm{OCH}_{2} \mathrm{CH}_{2} \mathrm{CH}_{2} \mathrm{CH}_{3}\right), 53.6\left(\mathrm{CH}_{2} \mathrm{Ph}\right), 66.8\left(\mathrm{~d},{ }^{2} J_{\mathrm{CP}}=5.7, \mathrm{OCH}_{2} \mathrm{CH}_{2} \mathrm{CH}_{2} \mathrm{CH}_{3}\right), 124.0\left(\mathrm{q},{ }^{1} J_{\mathrm{CF}}=272.2, \mathrm{CF}_{3}\right)$, $121.7\left(\mathrm{~d},{ }^{1} J_{\mathrm{CP}}=218.2, \mathrm{P}(\mathrm{O}) \mathrm{C}=\right), 125.7\left(\mathrm{q},{ }^{3} J_{\mathrm{CF}}=3.8, \mathrm{C}_{3^{\prime}}\right), 128.2\left(\mathrm{C}_{2}\right), 128.7\left(\mathrm{C}_{3}\right), 129.2\left(\mathrm{C}_{1}, \mathrm{C}_{2^{\prime}}\right), 130.1$ $\left(\mathrm{C}_{4}\right), 130.7\left(\mathrm{q},{ }^{2} J_{\mathrm{CF}}=32.6, \mathrm{C}_{4^{\prime}}\right), 139.9\left(\mathrm{C}_{1^{\prime}}\right), 153.6\left(\mathrm{~d},{ }^{2} J_{\mathrm{CP}}=18.9, \mathrm{PhC}=\right) ;[\mathrm{M}+\mathrm{H}]^{+}$found $=496.1936$, $\mathrm{C}_{24} \mathrm{H}_{30} \mathrm{~N}_{3} \mathrm{O}_{3} \mathrm{~F}_{3}$ P requires 496.1976 .

Dimethyl (1-octyl-4-phenyl-1,2,3-triazol-5-yl)phosphonate (23): yield: $43 \%(0.16 \mathrm{~g})$, colorless oil; ${ }^{31} \mathrm{P}$ NMR $\left(\mathrm{CDCl}_{3}\right) \delta 8.0 ;{ }^{1} \mathrm{H}$ NMR $\left(\mathrm{CDCl}_{3}\right) \delta 0.81\left(\mathrm{t}, 3 \mathrm{H},{ }^{3} J_{\mathrm{HH}}=6.9, \mathrm{NCH}_{2}\left(\mathrm{CH}_{2}\right)_{6} \mathrm{CH}_{3}\right), 1.12-1.37(\mathrm{~m}$, $\left.10 \mathrm{H}, \mathrm{NCH}_{2} \mathrm{CH}_{2}\left(\mathrm{CH}_{2}\right)_{5} \mathrm{CH}_{3}\right), 1.82-2.02\left(\mathrm{~m}, 2 \mathrm{H}, \mathrm{NCH}_{2} \mathrm{CH}_{2}\left(\mathrm{CH}_{2}\right)_{5} \mathrm{CH}_{3}\right), 3.58\left(\mathrm{~d}, 6 \mathrm{H},{ }^{3} J_{\mathrm{HP}}=11.6\right.$, $\left.\mathrm{OCH}_{3}\right), 4.68\left(\mathrm{t}, 2 \mathrm{H},{ }^{3} J_{\mathrm{HH}}=7.5, \mathrm{NCH}_{2}\left(\mathrm{CH}_{2}\right)_{6} \mathrm{CH}_{3}\right), 7.29-7.45\left(\mathrm{~m}, 3 \mathrm{H}, \mathrm{C}_{3} \mathrm{H}, \mathrm{C}_{4} \mathrm{H}\right), 7.65(\mathrm{dd}, 2 \mathrm{H}$, $\left.{ }^{3} J_{\mathrm{HH}}=6.5, J_{\mathrm{HH}}=3.3, \mathrm{C}_{2} \mathrm{H}\right) ;{ }^{13} \mathrm{C} \mathrm{NMR}\left(\mathrm{CDCl}_{3}\right) \delta 14.2\left(\mathrm{NCH}_{2}\left(\mathrm{CH}_{2}\right)_{6} \mathrm{CH}_{3}\right), 22.7\left(\mathrm{~N}_{(}\left(\mathrm{CH}_{2}\right)_{6} \mathrm{CH}_{2} \mathrm{CH}_{3}\right), 26.7$

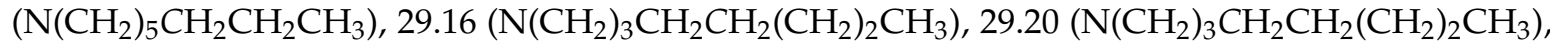

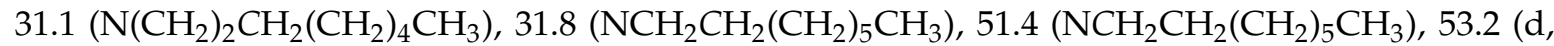
$\left.{ }^{2} J_{\mathrm{CP}}=5.6, \mathrm{OCH}_{3}\right), 120.6\left(\mathrm{~d},{ }^{1} J_{\mathrm{CP}}=221.5, \mathrm{P}(\mathrm{O}) \mathrm{C}=\right), 128.2\left(\mathrm{C}_{2}\right), 129.1\left(\mathrm{C}_{1}\right), 129.3\left(\mathrm{C}_{3}\right), 130.2\left(\mathrm{C}_{4}\right), 153.5(\mathrm{~d}$, $\left.{ }^{2} J_{\mathrm{CP}}=20.1, \mathrm{PhC}=\right) ;[\mathrm{M}+\mathrm{H}]^{+}$found $=366.1930, \mathrm{C}_{18} \mathrm{H}_{29} \mathrm{~N}_{3} \mathrm{O}_{3} \mathrm{P}$ requires 366.1946 .

Diethyl (1-octyl-4-phenyl-1,2,3-triazol-5-yl)phosphonate (24): yield: $58 \%(0.23 \mathrm{~g})$, colorless oil; ${ }^{31} \mathrm{P}$ NMR $\left(\mathrm{CDCl}_{3}\right) \delta 5.0 ;{ }^{1} \mathrm{H}$ NMR $\left(\mathrm{CDCl}_{3}\right) \delta 0.88\left(\mathrm{t}, 3 \mathrm{H},{ }^{3} J_{\mathrm{HH}}=6.6, \mathrm{NCH}_{2}\left(\mathrm{CH}_{2}\right)_{6} \mathrm{CH}_{3}\right), 1.16(\mathrm{t}, 6 \mathrm{H}$, $\left.{ }^{3} J_{\mathrm{HH}}=7.1, \mathrm{OCH}_{2} \mathrm{CH}_{2} \mathrm{CH}_{2} \mathrm{CH}_{3}\right), 1.22-1.47\left(\mathrm{~m}, 10 \mathrm{H}, \mathrm{NCH}_{2} \mathrm{CH}_{2}\left(\mathrm{CH}_{2}\right)_{5} \mathrm{CH}_{3}\right), 1.93-2.06(\mathrm{~m}, 2 \mathrm{H}$, $\left.\mathrm{NCH}_{2} \mathrm{CH}_{2}\left(\mathrm{CH}_{2}\right)_{5} \mathrm{CH}_{3}\right), 3.83-4.01\left(\mathrm{~m}, 2 \mathrm{H}, \mathrm{OCH}_{2} \mathrm{CH}_{3}\right), 4.01-4.19\left(\mathrm{~m}, 2 \mathrm{H}, \mathrm{OCH}_{2} \mathrm{CH}_{3}\right), 4.76(\mathrm{t}, 2 \mathrm{H}$, $\left.{ }^{3} J_{\mathrm{HH}}=7.5, \mathrm{NCH}_{2}\left(\mathrm{CH}_{2}\right)_{6} \mathrm{CH}_{3}\right), 7.34-7.48\left(\mathrm{~m}, 3 \mathrm{H}, \mathrm{C}_{3} \mathrm{H}, \mathrm{C}_{4} \mathrm{H}\right), 7.75\left(\mathrm{dd}, 2 \mathrm{H},{ }^{3} J_{\mathrm{HH}}=6.4, J_{\mathrm{HH}}=2.8, \mathrm{C}_{2} \mathrm{H}\right)$;

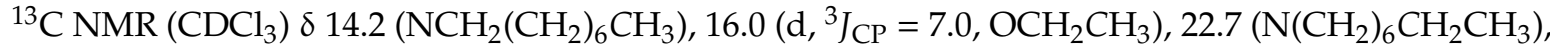
$26.7\left(\mathrm{~N}_{(}\left(\mathrm{CH}_{2}\right)_{5} \mathrm{CH}_{2} \mathrm{CH}_{2} \mathrm{CH}_{3}\right), 29.19\left(\mathrm{~N}\left(\mathrm{CH}_{2}\right)_{3} \mathrm{CH}_{2} \mathrm{CH}_{2}\left(\mathrm{CH}_{2}\right)_{2} \mathrm{CH}_{3}\right), 29.21\left(\mathrm{~N}\left(\mathrm{CH}_{2}\right)_{3} \mathrm{CH}_{2} \mathrm{CH}_{2}\left(\mathrm{CH}_{2}\right)_{2} \mathrm{CH}_{3}\right)$,

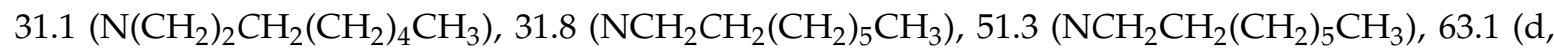
$\left.{ }^{2} J_{\mathrm{CP}}=5.5, \mathrm{OCH}_{2} \mathrm{CH}_{3}\right), 121.7\left(\mathrm{~d},{ }^{1} J_{\mathrm{CP}}=220.2, \mathrm{P}(\mathrm{O}) \mathrm{C}=\right), 128.1\left(\mathrm{C}_{2}\right), 129.0\left(\mathrm{C}_{1}\right), 129.5\left(\mathrm{C}_{3}\right), 130.5\left(\mathrm{C}_{4}\right)$, $153.2\left(\mathrm{~d},{ }^{2} J_{\mathrm{CP}}=20.0, \mathrm{PhC}=\right) ;[\mathrm{M}+\mathrm{H}]^{+}$found $=394.2241, \mathrm{C}_{20} \mathrm{H}_{33} \mathrm{~N}_{3} \mathrm{O}_{3} \mathrm{P}$ requires 394.2259.

Dibutyl (1-octyl-4-phenyl-1,2,3-triazol-5-yl)phosphonate (25): yield: 50\% (0.22 g), colorless oil; ${ }^{31} \mathrm{P}$ NMR $\left(\mathrm{CDCl}_{3}\right) \delta 5.3 ;{ }^{1} \mathrm{H}$ NMR $\left(\mathrm{CDCl}_{3}\right) \delta 0.75-0.97\left(\mathrm{~m}, 9 \mathrm{H}, \mathrm{OCH}_{2} \mathrm{CH}_{2} \mathrm{CH}_{2} \mathrm{CH}_{3}, \mathrm{NCH}_{2}\left(\mathrm{CH}_{2}\right)_{6} \mathrm{CH}_{3}\right), 1.13-1.55$ (m, $\left.18 \mathrm{H}, \mathrm{OCH}_{2} \mathrm{CH}_{2} \mathrm{CH}_{2} \mathrm{CH}_{3}, \mathrm{NCH}_{2} \mathrm{CH}_{2}\left(\mathrm{CH}_{2}\right)_{5} \mathrm{CH}_{3}\right), 1.89-2.07$ (m, $\left.2 \mathrm{H}, \mathrm{NCH}_{2} \mathrm{CH}_{2}\left(\mathrm{CH}_{2}\right)_{5} \mathrm{CH}_{3}\right)$, 3.75-3.95 (m, 2H, OCH $\left.\mathrm{CH}_{2} \mathrm{CH}_{2} \mathrm{CH}_{3}\right), 3.95-4.14\left(\mathrm{~m}, 2 \mathrm{H}, \mathrm{OCH}_{2} \mathrm{CH}_{2} \mathrm{CH}_{2} \mathrm{CH}_{3}\right), 4.77\left(\mathrm{t}, 2 \mathrm{H},{ }^{3} \mathrm{~J}_{\mathrm{HH}}=7.4\right.$, $\left.\mathrm{NCH}_{2}\left(\mathrm{CH}_{2}\right)_{6} \mathrm{CH}_{3}\right), 7.34-7.51\left(\mathrm{~m}, 3 \mathrm{H}, \mathrm{C}_{3} \mathrm{H}, \mathrm{C}_{4} \mathrm{H}\right), 7.74\left(\mathrm{dd}, 2 \mathrm{H},{ }^{3} J_{\mathrm{HH}}=6.7, J_{\mathrm{HH}}=3.1, \mathrm{C}_{2} \mathrm{H}\right) ;{ }^{13} \mathrm{C}$ NMR $\left(\mathrm{CDCl}_{3}\right) \delta 13.6\left(\mathrm{OCH}_{2} \mathrm{CH}_{2} \mathrm{CH}_{2} \mathrm{CH}_{3}\right), 14.2\left(\mathrm{NCH}_{2}\left(\mathrm{CH}_{2}\right)_{6} \mathrm{CH}_{3}\right), 18.7\left(\mathrm{OCH}_{2} \mathrm{CH}_{2} \mathrm{CH}_{2} \mathrm{CH}_{3}\right)$, $22.8\left(\mathrm{~N}\left(\mathrm{CH}_{2}\right)_{6} \mathrm{CH}_{2} \mathrm{CH}_{3}\right), 26.7\left(\mathrm{~N}\left(\mathrm{CH}_{2}\right)_{5} \mathrm{CH}_{2} \mathrm{CH}_{2} \mathrm{CH}_{3}\right), 29.3\left(\mathrm{~N}_{2}\left(\mathrm{CH}_{2}\right)_{3} \mathrm{CH}_{2} \mathrm{CH}_{2}\left(\mathrm{CH}_{2}\right)_{2} \mathrm{CH}_{3}\right), 29.8$ $\left(\mathrm{N}\left(\mathrm{CH}_{2}\right)_{2} \mathrm{CH}_{2}\left(\mathrm{CH}_{2}\right)_{4} \mathrm{CH}_{3}\right), 31.2\left(\mathrm{~N}\left(\mathrm{CH}_{2} \mathrm{CH}_{2}\left(\mathrm{CH}_{2}\right)_{5} \mathrm{CH}_{3}\right), 32.2\left(\mathrm{~d},{ }^{3} J_{\mathrm{CP}}=6.9, \mathrm{OCH}_{2} \mathrm{CH}_{2} \mathrm{CH}_{2} \mathrm{CH}_{3}\right)\right.$, $51.4\left(\mathrm{~N}_{(}\left(\mathrm{CH}_{2} \mathrm{CH}_{2}\left(\mathrm{CH}_{2}\right)_{5} \mathrm{CH}_{3}\right), 66.8\left(\mathrm{~d},{ }^{2} J_{\mathrm{CP}}=5.8, \mathrm{OCH}_{2} \mathrm{CH}_{2} \mathrm{CH}_{2} \mathrm{CH}_{3}\right), 121.6\left(\mathrm{~d},{ }^{1} J_{\mathrm{CP}}=220.2, \mathrm{P}(\mathrm{O}) \mathrm{C}=\right)\right.$, $128.2\left(\mathrm{C}_{2}\right), 129.0\left(\mathrm{C}_{1}\right), 129.4\left(\mathrm{C}_{3}\right), 130.5\left(\mathrm{C}_{4}\right), 153.2\left(\mathrm{~d},{ }^{2} J_{\mathrm{CP}}=19.9, \mathrm{PhC}=\right) ;[\mathrm{M}+\mathrm{H}]^{+}$found $=450.2862$, $\mathrm{C}_{24} \mathrm{H}_{41} \mathrm{~N}_{3} \mathrm{O}_{3}$ P requires 450.2885 .

Dibutyl (1-isooctyl-4-phenyl-1,2,3-triazol-5-yl)phosphonate (26): yield: $28 \%(0.13 \mathrm{~g})$, colorless oil; ${ }^{31} \mathrm{P}$ NMR $\left(\mathrm{CDCl}_{3}\right) \delta 3.0 ;{ }^{1} \mathrm{H}$ NMR $\left(\mathrm{CDCl}_{3}\right) \delta 0.77-0.96\left(\mathrm{~m}, 12 \mathrm{H}, \mathrm{OCH}_{2} \mathrm{CH}_{2} \mathrm{CH}_{2} \mathrm{CH}_{3}\right.$, $\left.\mathrm{NCH}_{2} \mathrm{CHCH}_{2} \mathrm{CH}_{3}, \mathrm{NCH}_{2} \mathrm{CH}\left(\mathrm{CH}_{2}\right)_{3} \mathrm{CH}_{3}\right), 1.16-1.53\left(\mathrm{~m}, 16 \mathrm{H}, \mathrm{OCH}_{2} \mathrm{CH}_{2} \mathrm{CH}_{2} \mathrm{CH}_{3}, \mathrm{NCH}_{2} \mathrm{CHCH}_{2} \mathrm{CH}_{3}\right.$, $\left.\mathrm{NCH}_{2} \mathrm{CH}\left(\mathrm{CH}_{2}\right)_{3} \mathrm{CH}_{3}\right), 2.06-2.20\left(\mathrm{~m}, 1 \mathrm{H}, \mathrm{NCH}_{2} \mathrm{CHCH}_{2} \mathrm{CH}_{3}\right), 3.77-3.94\left(\mathrm{~m}, 2 \mathrm{H}, \mathrm{OCH}_{2} \mathrm{CH}_{2} \mathrm{CH}_{2} \mathrm{CH}_{3}\right)$, 3.97-4.11 (m, 2H, OCH $\left.\mathrm{CH}_{2} \mathrm{CH}_{2} \mathrm{CH}_{3}\right), 4.69\left(\mathrm{~d}, 2 \mathrm{H},{ }^{3} J_{\mathrm{HH}}=7.5, \mathrm{NCH}_{2} \mathrm{CHCH}_{2} \mathrm{CH}_{3}\right), 7.34-7.45$ $\left(\mathrm{m}, 3 \mathrm{H}, \mathrm{C}_{3} \mathrm{H}, \mathrm{C}_{4} \mathrm{H}\right), 7.75\left(\mathrm{dd}, 2 \mathrm{H},{ }^{3} J_{\mathrm{HH}}=6.4, J_{\mathrm{HH}}=3.3, \mathrm{C}_{2} \mathrm{H}\right) ;{ }^{13} \mathrm{C}$ NMR $\left(\mathrm{CDCl}_{3}\right) \delta 10.5$ $\left(\mathrm{NCH}_{2} \mathrm{CHCH}_{2} \mathrm{CH}_{3}\right), 13.5\left(\mathrm{OCH}_{2} \mathrm{CH}_{2} \mathrm{CH}_{2} \mathrm{CH}_{3}\right), 14.1\left(\mathrm{NCH}_{2} \mathrm{CH}\left(\mathrm{CH}_{2}\right)_{3} \mathrm{CH}_{3}\right), 18.7\left(\mathrm{OCH}_{2} \mathrm{CH}_{2} \mathrm{CH}_{2} \mathrm{CH}_{3}\right)$, $23.0\left(\mathrm{NCH}_{2} \mathrm{CH}\left(\mathrm{CH}_{2}\right)_{2} \mathrm{CH}_{2} \mathrm{CH}_{3}\right), 23.7\left(\mathrm{NCH}_{2} \mathrm{CHCH}_{2} \mathrm{CH}_{3}\right), 28.5\left(\mathrm{NCH}_{2} \mathrm{CHCH}_{2} \mathrm{CH}_{2} \mathrm{CH}_{2} \mathrm{CH}_{3}\right), 30.4$ $\left(\mathrm{NCH}_{2} \mathrm{CHCH}_{2}\left(\mathrm{CH}_{2}\right)_{2} \mathrm{CH}_{3}\right), 32.1\left(\mathrm{~d},{ }^{3} \mathrm{~J}_{\mathrm{CP}}=6.9, \mathrm{OCH}_{2} \mathrm{CH}_{2} \mathrm{CH}_{2} \mathrm{CH}_{3}\right), 40.5\left(\mathrm{NCH}_{2} \mathrm{CHCH}_{2} \mathrm{CH}_{3}\right), 54.8$ $\left(\mathrm{NCH}_{2} \mathrm{CHCH}_{2} \mathrm{CH}_{3}\right), 66.7\left(\mathrm{~d},{ }^{2} J_{\mathrm{CP}}=5.8, \mathrm{OCH}_{2} \mathrm{CH}_{2} \mathrm{CH}_{2} \mathrm{CH}_{3}\right), 121.9\left(\mathrm{~d},{ }^{1} J_{\mathrm{CP}}=221.1, \mathrm{P}(\mathrm{O}) \mathrm{C}=\right), 128.1\left(\mathrm{C}_{2}\right)$, $128.9\left(\mathrm{C}_{1}\right), 129.4\left(\mathrm{C}_{3}\right), 130.5\left(\mathrm{C}_{4}\right), 153.2\left(\mathrm{~d},{ }^{2} J_{\mathrm{CP}}=19.8, \mathrm{PhC}=\right) ;[\mathrm{M}+\mathrm{H}]^{+}$found $=450.2855, \mathrm{C}_{24} \mathrm{H}_{41} \mathrm{~N}_{3} \mathrm{O}_{3} \mathrm{P}$ requires 450.2885 . 


\subsection{Biological Evaluation}

\subsubsection{Cell Culture}

Cells were purchased from the American Type Culture Collection (ATCC, Manassas, VA, USA). Human lung adenocarcinoma A549 cells were maintained in Dulbecco's Modified Eagle Medium (DMEM), while mouse fibroblast NIH/3T3 and human promyelocytic leukemia HL-60 cells were maintained in Roswell Park Memorial Institute 1640 medium (RPMI-1640) containing 10\% FCS. Media were supplemented with $2 \mathrm{mM}$ GlutaMAX, $100 \mathrm{U} / \mathrm{mL}$ penicillin, and $100 \mu \mathrm{g} / \mathrm{mL}$ streptomycin (Life Technologies, Carlsbad, California, USA). Cell cultures were maintained at $37{ }^{\circ} \mathrm{C}$ in a humidified incubator in an atmosphere of $5 \% \mathrm{CO}_{2}$ (Sanyo, Japan).

\subsubsection{Antibacterial Activity}

All reagents were purchased from Sigma-Aldrich (Hungary, Budapest). E. coli-GFP and B. subtilis-GFP bacteria were grown in Lysogeny Broth (Luria-Bertani broth, LB, 10 g tryptone, 5 g yeast extract, $10 \mathrm{~g} / \mathrm{L} \mathrm{NaCl}, \mathrm{pH} 7.0)$ medium overnight $(\mathrm{ON})$ at $37^{\circ} \mathrm{C}$ in an incubator with continuous shaking [44,45]. The ON bacterial culture was diluted (E. coli-GFP: 1:10000, B. subtilis-GFP: 1:1000) in LB medium containing $10 \mu \mathrm{g} / \mathrm{mL}$ ampicillin. Two hundred microliters of diluted $E$. coli suspension per well were transferred to 96-well plates and different agents were added in the appropriate concentration, then incubated in a shaker $(600 \mathrm{rpm})$ for $3 \mathrm{~h}$ at $37^{\circ} \mathrm{C}$. Test compounds were dissolved in 3-fold amounts of dimethyl sulfoxide (DMSO). Cells were treated with an increasing concentration of test compounds $(1-30 \mu \mathrm{M})$. Doxycyclin $\left(\mathrm{IC}_{50}=0.10 \pm 0.02\right.$ and $0.04 \pm 0.01 \mu \mathrm{M}$ for E. coli and B. subtilis) and gentamicin $\left(\mathrm{IC}_{50}=4.23 \pm 0.99\right.$ and $0.49 \pm 0.14 \mu \mathrm{M}$ for $E$. coli and B. subtilis) were used as positive controls. For induction of the GFP expression IPTG $(0.1 \mathrm{mM}$ final concentration) was added to each well and incubated for $3 \mathrm{~h}$ at $37^{\circ} \mathrm{C}$.

The following incubation samples were centrifuged at $2750 \mathrm{rpm}$ at room temperature (RT) for 5 min and washed twice with $200 \mu \mathrm{L}$ PBS, with a centrifugation step between the two washes. After a third centrifugation step, the bacterial cells were suspended in $100 \mu \mathrm{L}$ PBS. The number of bacteria was estimated according to the fluorimetric measurements. The fluorescence of the bacterial cells was measured by the Victor ${ }^{\mathrm{TM}} 1420$ Multilabel Counter (Perkin Elmer, Waltham, MA, USA) at 485/535 nm for $1 \mathrm{sec}$ per well controlled by Wallac 1420 Manager software. Each treatment was repeated in at least 2 wells per plate during the experiments. Percentage fluorescence intensity based on the quantity of E. coli-GFP cells was calculated using untreated control values as $100 \%$. Error was represented by standard deviation (SD). $\mathrm{IC}_{50}$ values (50\% inhibiting concentration) were calculated by GraphPad Prism $^{\circledR} 5$ (La Jolla, CA, USA).

\subsubsection{Cytotoxicity Assay}

Cytotoxicity of the synthesized molecules was determined on A549, NIH/3T3 and HL-60 cells using the fluorescent Resazurin assay as described previously [46].

Briefly, cells (A549 and NIH/3T3: 6000, HL-60: 120.000 cells/well) were seeded into 96-well plates (Corning Life Sciences) in media and incubated overnight. Test compounds were dissolved in three-fold amounts of dimethyl sulfoxide (DMSO). Cells were treated with an increasing concentration of test compounds $(1-30 \mu \mathrm{M})$. Positive controls were doxorubicin for A549 and NIH/3T3 (IC $50=0.31 \pm 0.24 \mu \mathrm{M}$ and $5.65 \pm 0.81 \mu \mathrm{M}$, respectively), and bortezomib for $\mathrm{HL60}\left(\mathrm{IC}_{50}=7.42 \pm 2.60 \mathrm{nM}\right)$. Cell viability was determined after $72 \mathrm{~h}$ incubation. Resazurin reagent (Sigma-Aldrich) was added at a final concentration of $25 \mu \mathrm{g} / \mathrm{mL}$. After a $2 \mathrm{~h}$ incubation at $37{ }^{\circ} \mathrm{C}$ in $5 \% \mathrm{CO}_{2}$, fluorescence $(530 \mathrm{~nm}$ excitation/580 $\mathrm{nm}$ emission) was recorded on a multimode microplate reader (Cytofluor4000, PerSeptive Biosytems). Viability was calculated with relation to untreated control cells and blank wells containing media without cells. $\mathrm{IC}_{50}$ values (50\% inhibiting concentration) were calculated by GraphPad Prism ${ }^{\circledR} 5$. A Student's t test was performed for individual test compound concentrations with relation to untreated control cell viability values. 


\section{Conclusions}

In summary, the synthesis of 1,2,3-triazol-5-yl-phosphonates was studied by the copper(I)-chloride-catalyzed three-component domino reaction of phenylacetylene, azides and dialkyl phosphites. The model reaction of phenylacetylene, benzyl azide and dibutyl phosphite was optimized in details. The effect of the atmosphere, the type of base, the catalyst and the solvent, as well as the molar ratio of the starting materials, the temperature and the reaction time were studied. Applying the approach developed, altogether 17 triazol-5-yl-phosphonate derivatives were synthesized and fully characterized, except two (12 and 14), all of them are new compounds. The biological activity of the compounds prepared was investigated in antibacterial activity and in vitro cytotoxicity assays. None of the synthesized 1,2,3-triazol-5-yl-phosphonates were active against selected Gram-negative bacteria, while the growth of Gram-positive bacteria was somewhat reduced. Several derivatives showed low or modest activity against the tested cell lines, two of them have the $\mathrm{IC}_{50}$ value in the 10 micromolar range against HL-60 cells.

Supplementary Materials: Supplementary data associated with this article are available online. Copies of ${ }^{31} \mathrm{P}$, ${ }^{1} \mathrm{H}$, and ${ }^{13} \mathrm{C}$ NMR spectra for all compounds synthesized are presented.

Author Contributions: E.B. and A.T. planned the experiments, A.T. and. E.T. carried out the experiments, P.T.S. performed the high-resolution mass spectrometric measurements, B.K. and L.H.J. performed the biological evaluation (screening), E.B., A.T., L.H.J. and L.G.P. wrote the paper. All authors have read and agreed to the published version of the manuscript.

Funding: The project was supported by the Hungarian Research Development and Innovation Office (FK123961). E.B. was supported by the János Bolyai Research Scholarship of the Hungarian Academy of Sciences (BO/00278/17/7). A.T. was supported by the ÚNKP-19-3-I-BME-391 New National Excellence Program of the Ministry for Innovation and Technology.

Conflicts of Interest: The authors declare no conflict of interest.

\section{References}

1. Moonen, K.; Laureyn, I.; Stevens, C.V. Synthetic methods for azaheterocyclic phosphonates and their biological activity. Chem. Rev. 2004, 104, 6177-6216. [CrossRef] [PubMed]

2. Bansal, R.K. (Ed.) Phosphorus Heterocycles II. In Topics in Heterocyclic Chemistry; Springer: Berlin, Germany, 2010; Volume 21, ISBN 978-3-642-12253-8.

3. Tappe, F.M.J.; Trepohl, V.T.; Oestreich, M. Transition-metal-catalyzed CP cross-coupling reactions. Synthesis 2010, 18, 3037-3062. [CrossRef]

4. Ali, T.E.; Abdel-Kariem, S.M. Methods for the synthesis of $\alpha$-heterocyclic/heteroaryl- $\alpha$-aminophosphonic acids and their esters. Arkivoc 2015, 2015, 246-287. [CrossRef]

5. Haji, M. Multicomponent Reactions: A simple and efficient route to heterocyclic phosphonates. Beilstein J. Org. Chem. 2016, 12, 1269-1301. [CrossRef] [PubMed]

6. Dömling, A.; Wang, W.; Wang, K. Chemistry and biology of multicomponent reactions. Chem. Rev. 2012, 112, 3083-3135. [CrossRef]

7. Müller, T.J.J. (Ed.) Multicomponent Reactions 1. In Science of Synthesis; Thieme: Stuttgart, Germany, 2014; ISBN 978-3-131-66881-3.

8. Katritzky, A.R.; Rees, C.W.; Scriven, C.W.V. (Eds.) Comprehensive Heterocyclic Chemistry; Elsevier Science: Oxford, UK, 1996; Volume 4, pp. 1-126.

9. Thirumurugan, P.; Matosiuk, D.; Jozwiak, K. Click chemistry for drug development and diverse chemical-biology applications. Chem. Rev. 2013, 113, 4905-4979. [CrossRef]

10. Lauria, A.; Delisi, R.; Mingoia, F.; Terenzi, A.; Martorana, A.; Barone, G.; Almerico, A.M. 1,2,3-Triazole in heterocyclic compounds, endowed with biological activity, through 1,3-dipolar cycloadditions. Eur. J. Org. Chem. 2014, 2014, 3289-3306. [CrossRef]

11. Dheer, D.; Singh, V.; Shankar, R. Medicinal attributes of 1,2,3-triazoles: Current developments. Bioorg. Chem. 2017, 71, 30-54. [CrossRef]

12. Bonandi, E.; Christodoulou, M.S.; Fumagalli, G.; Perdicchia, D.; Rastelli, G.; Passarella, D. The 1,2,3-triazole ring as a bioisostere in medicinal chemistry. Drug Discov. Today 2017, 22, 1572-1581. [CrossRef] 
13. Rani, A.; Singh, G.; Singh, A.; Maqbool, U.; Kaur, G.; Singh, J. CuAAC-ensembled 1,2,3-triazole-linked isosteres as pharmacophores in drug discovery: Review. RSC Adv. 2020, 10, 5610-5635. [CrossRef]

14. Lal, K.; Yadav, P.; Kumar, A.; Kumar, A.; Paul, A.K. Design, synthesis, characterization, antimicrobial evaluation and molecular modeling studies of some dehydroacetic acid-chalcone-1,2,3-triazole hybrids. Bioorg. Chem. 2018, 77, 236-244. [CrossRef] [PubMed]

15. Kategaonkar, A.H.; Shinde, P.V.; Kategaonkar, A.H.; Pasale, S.K.; Shingate, B.B.; Shingare, M.S. Synthesis and biological evaluation of new 2-chloro-3-((4-phenyl-1H-1,2,3-triazol-1-yl)methyl)quinoline derivatives via click chemistry approach. Eur. J. Med. Chem. 2010, 45, 3142-3146. [CrossRef] [PubMed]

16. Garudachari, B.; Isloor, A.M.; Satyanarayana, M.N.; Fun, H.K.; Hegde, G. Click chemistry approach: Regioselective one-pot synthesis of some new 8-trifluoromethylquinoline based 1,2,3-triazoles as potent antimicrobial agents. Eur. J. Med. Chem. 2014, 74, 324-332. [CrossRef] [PubMed]

17. De Souza-Fagundes, E.M.; Delp, J.; Prazeres, P.D.M.; Marques, B.; Maria, A.; Carmo, L.; Henrique, P.; Stroppa, F.; Glanzmann, N.; Kisitu, J.; et al. Correlation of structural features of novel 1,2,3-triazoles with their neurotoxic and tumoricidal properties. Chem.-Biol. Interact. 2018, 291, 253-263. [CrossRef]

18. Wu, M.J.; Wu, D.M.; Chen, J.B.; Zhao, J.F.; Gong, L.; Gong, Y.X.; Li, Y.; Yang, X.D.; Zhang, H. Synthesis and anti-proliferative activity of allogibberic acid derivatives containing 1,2,3-triazole pharmacophore. Bioorg. Med. Chem. Lett. 2018, 28, 2543-2549. [CrossRef]

19. Praveena, K.S.S.; Shivaji Ramarao, E.V.V.; Murthy, N.Y.S.; Akkenapally, S.; Ganesh Kumar, C.; Kapavarapu, R.; Pal, S. Design of new hybrid template by linking quinoline, triazole and dihydroquinoline pharmacophoric groups: A greener approach to novel polyazaheterocycles as cytotoxic agents. Bioorg. Med. Chem. Lett. 2015, 25, 1057-1063. [CrossRef]

20. Li, L.; Hao, G.; Zhu, A.; Fan, X.; Zhang, G.; Zhang, L. A copper(I)-catalyzed three-component domino process: Assembly of complex 1,2,3-triazolyl-5-phosphonates from azides, alkynes, and H-phosphates. Chem. Eur. J. 2013, 19, 14403-14406. [CrossRef]

21. Radi, S.; Lazrek, H.B. Synthesis and biological activity of new 1,2,3-triazole acyclonucleosides analogues of ACV. J. Chem. Res. Synop. 2002, 264-266. [CrossRef]

22. Costa, C.P.C.; Boechat, N.; Bastos, M.M.; da Silva, F.D.C.; Marttorelli, A.; Souza, M.L.T.; Baptista, S.M.; Hoelz, V.B.L.; Cafffarena, R.E. New Efavirenz derivatives and 1,2,3-triazolyl-phosphonates as inhibitors of reverse transcriptase of HIV-1. Curr. Top. Med. Chem. 2018, 2018, 1494-1505. [CrossRef]

23. McAllister, T.E.; Horner, K.A.; Webb, M.E. Evaluation of the interaction between phosphohistidine analogues and phosphotyrosine binding domains. Chem. Bio. Chem. 2014, 15, 1088-1091. [CrossRef]

24. Kee, J.M.; Villani, B.; Carpenter, L.R.; Muir, T.W. Development of stable phosphohistidine analogues. J. Am. Chem. Soc. 2010, 132, 14327-14329. [CrossRef] [PubMed]

25. Mukai, S.; Flematti, G.R.; Byrne, L.T.; Besant, P.G.; Attwood, P.V.; Piggott, M.J. Stable triazolylphosphonate analogues of phosphohistidine. Amino Acids. 2012, 43, 857-874. [CrossRef] [PubMed]

26. Huisgen, R. 1,3-Dipolar cycloadditions. Past and future. Angew. Chem. Int. Ed. 1963, 2, 565-632. [CrossRef]

27. Huisgen, R. Kinetics and mechanism of 1,3-dipolar cycloadditions. Angew. Chem. Int. Ed. 1963, 2, $633-696$. [CrossRef]

28. Hall, R.G.; Trippet, S. The preparation and Diels-Alder reactivity of ethyl (diethoxyphosphinyl)propynoate. Tetrahedron Lett. 1982, 23, 2603-2604. [CrossRef]

29. Shen, Y.; Zheng, J.; Xin, Y.; Lin, Y.; Qi, M. Synthesis of perfluoroalkylated heterocyclic phosphonates. J. Chem. Soc. Perkin Trans. 1 1995, 8, 997-999. [CrossRef]

30. Huang, P.; Su, Q.; Dong, W.; Zhang, Y.; An, D. BrØnsted/Lewis acids-promoted selective preparations of 3-hetero quinolines or 4/5-hetero triazoles from azides and hetero-alkynes. Tetrahedron 2017, 73, 4275-4284. [CrossRef]

31. Artyushin, O.I.; Matveeva, E.V.; Bushmarinov, I.S.; Odinets, I.L. Water as a promoting media for 1,3-dipolar cycloaddition of phosphorylated azides to internal alkynes. Arkivoc 2012, 4, 252-263. [CrossRef]

32. Louërat, F.; Bougrin, K.; Loupy, A.; de Retana, A.M.O.; Pagalday, J.; Palacios, F. Cycloaddition reactions of azidomethyl phosphonate with acetylenes and enamines. Synthesis of triazoles. Heterocycles 1998, 48, 161-170. [CrossRef]

33. Thomas, J.; Jubi, J.; Parekh, N.; Dehaen, W. A metal-free three-component reaction for the regioselective synthesis of 1,4,5-trisubstituted 1,2,3-triazoles. Angew. Chem. Int. Ed. 2014, 53, 10155-10160. [CrossRef] 
34. Ahamad, S.; Kant, R.; Mohanan, K. Metal-free three-component domino approach to phosphonylated triazolines and triazoles. Org. Lett. 2016, 18, 280-283. [CrossRef] [PubMed]

35. Tripolszky, A.; Tóth, E.; Bálint, E. Synthesis of 1,2,3-triazolyl-5-diethylphosphonate by domino reaction. Phosphorus Sulfur Silicon Relat. Elem. 2019, 194, 377-378. [CrossRef]

36. Gann, A.W.; Amoroso, J.W.; Einck, V.J.; Rice, W.P.; Chambers, J.J.; Schnarr, N.A. A photoinduced, benzyne click reaction. Org. Lett. 2014, 16, 2003-2005. [CrossRef] [PubMed]

37. Bao, M.; Lu, W.; Su, H.; Qiu, L.; Xu, X. A convergent formal [4 + 2] cycloaddition of 1,6-diynes and benzyl azides: Construction of spiro-polyheterocycles. Org. Biomol. Chem. 2018, 16, 3258-3265. [CrossRef]

38. Wang, X.; Mei, T.S.; Yu, J.Q. Versatile Pd(OTf) $2 \cdot 2 \mathrm{H}_{2} \mathrm{O}$-catalyzed ortho-fluorination using NMP as a promoter. J. Am. Chem. Soc. 2009, 131, 7520-7521. [CrossRef]

39. Colombano, G.; Albani, C.; Ottonello, G.; Ribeiro, A.; Scarpelli, R.; Tarozzo, G.; Daglian, J.; Jung, K.M.; Piomelli, D.; Bandiera, T. O-(Triazolyl)methyl carbamates as a novel and potent class of fatty acid amide hydrolase (FAAH) inhibitors. Chem. Med. Chem. 2014, 10, 380-395. [CrossRef]

40. Tesch, M.; Kudruk, S.; Letzel, M.; Studer, A. Orthogonal click postfunctionalization of alternating copolymers prepared by nitroxide-mediated polymerization. Chem. Eur. J. 2017, 23, 5915-5919. [CrossRef]

41. Colombano, G.; Travelli, C.; Galli, U.; Caldarelli, A.; Chini, M.G.; Canonico, P.L.; Sorba, G.; Bifulco, G.; Tron, G.C.; Genazzani, A.A. A novel potent nicotinamide phosphoribosyltransferase inhibitor synthesized via click chemistry. J. Med. Chem. 2010, 53, 616-623. [CrossRef]

42. Swetha, M.; Ramana, P.V.; Shirodkar, S.G. Simple and efficient method for the synthesis of azides in waterTHF solvent system. Org. Prep. Proced. Int. 2011, 43, 348-353. [CrossRef]

43. Bálint, E.; Tajti, Á.; Tóth, N.; Keglevich, G. Continuous flow alcoholysis of dialkyl H-phosphonates with aliphatic alcohols. Molecules 2018, 23, 1618. [CrossRef]

44. Csörgő, B.; Fehér, T.; Tímár, E.; Blattner, F.R.; Pósfai, G. Low-mutation-rate, reduced-genome Escherichia coli: An improved host for faithful maintenance of engineered genetic constructs. Microb. Cell Fact. 2012, 11, 11-24. [CrossRef] [PubMed]

45. Phan, T.T.; Tran, L.T.; Schumann, W.; Nguyen, H.D. Development of Pgrac100-based expression vectors allowing high protein production levels in Bacillus subtilis and relatively low basal expression in Escherichia coli. Microb. Cell Fact. 2015, 14, 72-81. [CrossRef] [PubMed]

46. Szebeni, G.J.; Balázs, A.; Madarász, I.; Pocz, G.; Ayaydin, F.; Kanizsai, I.; Fajka-Boja, R.; Alföldi, R.; Hackler, L., Jr.; Puskás, L.G. Achiral mannich-base curcumin analogs induce unfolded protein response and mitochondrial membrane depolarization in panc-1 cells. Int. J. Mol. Sci. 2017, 18, 2105. [CrossRef] [PubMed]

Sample Availability: Samples of the compounds $\mathbf{8}$ and 11-26 are available from the authors.

(C) 2020 by the authors. Licensee MDPI, Basel, Switzerland. This article is an open access article distributed under the terms and conditions of the Creative Commons Attribution (CC BY) license (http://creativecommons.org/licenses/by/4.0/). 